\title{
Cannabinoid Receptor Activation Prevents the Effects of Chronic Mild Stress on Emotional Learning and LTP in a Rat Model of Depression
}

\author{
Amir Segev 1,4, Adva S Rubin ${ }^{1,4}$, Hila Abush', Gal Richter-Levin ${ }^{1,2,3}$ and Irit Akirav*,' \\ 'Department of Psychology, University of Haifa, Haifa, Israel; ²Department of Neurobiology, University of Haifa, Haifa, Israel; \\ ${ }^{3}$ The Institute for the Study of Affective Neuroscience, University of Haifa, Haifa, Israel
}

\begin{abstract}
Most psychiatric disorders are characterized by emotional memory or learning disturbances. Chronic mild stress (CMS) is a common animal model for stress-induced depression. Here we examined whether 3 days of treatment using the CBI/2 receptor agonist WIN55,212-2 could ameliorate the effects of CMS on emotional learning (ie, conditioned avoidance and extinction), long-term potentiation (LTP) in the hippocampal-accumbens pathway, and depression-like symptoms (ie, coping with stress behavior, anhedonia, and weight changes). We also examined whether the ameliorating effects of WIN55,2 I2-2 on behavior and physiology after CMS are mediated by CBI and glucocorticoid receptors (GRs). Rats were exposed to CMS or handled on days I-2I. The agonist WIN55,2 I2-2 or vehicle were administered on days 19-2I (IP; $0.5 \mathrm{mg} / \mathrm{kg}$ ) and behavioral and electrophysiological measures were taken on days 23 and 28. The CBI receptor antagonist AM25I (IP; $0.3 \mathrm{mg} / \mathrm{kg}$ ) or the GR antagonist RU-38486 (IP; I0 mg/kg) were co-administered with WIN55,2I2-2. Our results show that CMS significantly modified physiological and behavioral reactions, as observed by the impairment in avoidance extinction and LTP in the hippocampal-accumbens pathway, and the alterations in depression-like symptoms, such as coping with stress behavior, weight gain, and sucrose consumption. The most significant effect observed in this study was that 3 days of WIN55,2 I2-2 administration prevented the CMS-induced alterations in emotional memory (ie, extinction) and plasticity. This effect was mediated by $C B I$ receptors as the CBI receptor antagonist AM25I prevented the ameliorating effects of WIN55,212-2 on extinction and LTP. The GR antagonist RU-38486 also prevented the CMS-induced alterations in extinction and plasticity, and when co-administered with WIN55,2 12-2, the preventive effects after CMS were maintained. The findings suggest that enhancing cannabinoid signaling could represent a novel approach to the treatment of cognitive deficits that accompany stress-related depression.

Neuropsychopharmacology (20 I4) 39, 919-933; doi:I0.1038/npp.2013.292; published online 13 November 2013
\end{abstract}

Keywords: WIN55; 212-2; extinction; LTP; depression; nucleus accumbens; glucocorticoid receptors

\section{INTRODUCTION}

Most psychiatric disorders are characterized by emotional memory or learning disturbances. These learning and memory alterations are not just secondary symptoms but are key components of these disorders. For example, patients with major depression have a memory bias with preferred storage and retrieval of negative information.

Chronic mild stress (CMS) is a common animal model for stress-induced depression (Willner et al, 1992). In CMS, animals are exposed to moderate stressors, such as food or water deprivation, overnight lighting, and changes in housing, for a relatively long time. The behavioral profile

\footnotetext{
*Correspondence: Dr I Akirav, Department of Psychology, University of Haifa, Mt Carmel, Haifa 31905, Israel, Tel: +972 48288268 ,

Fax: +972 48263157 , E-mail: irit.akirav@gmail.com

${ }^{4}$ These authors contributed equally to the work.

Received 18 April 2013; revised 8 October 2013; accepted 16 October 2013; accepted article preview online 21 October 2013
}

of animals that have been exposed to CMS has high face validity. It includes reduction of sucrose intake and impairments in brain stimulation reward as a measure for anhedonia, decreased sexual activity and self-care, and changes in sleep and appetite (Grønli et al, 2004; Willner, 2005). The model also has high predictive validity, as the symptoms are reversed with chronic antidepressant treatment but not with acute treatment (Willner, 2005; Willner et al, 1992).

Long-term potentiation (LTP) is one of the prime candidates for mediating learning and memory as well as many other forms of experience-dependent plasticity. The successful $v s$ unsuccessful induction of LTP can serve as a 'diagnostic' measure with which to assess the functional state of a brain structure (Diamond et al, 2007). Growing attention has been focused on plasticity in the ventral Subiculum (vSub)-nucleus accumbens (NAc) pathway (Abush and Akirav, 2012, 2013; O'Donnell and Grace, 1995) as there is growing evidence for a role of the NAc in the regulation of mood and motivation under normal 
conditions and in mediating many of the prominent behavioral abnormalities seen in depression and other mood disorders (for a review, see Nestler and Carlezon, 2006).

The NAc is involved in mediating stress-related dysfunction (Nestler et al, 2002; Willner et al, 1992), and with input from the vSub, it mediates goal-directed behavior and is important for aspects of cognitive function, such as contextdependent processing (Belujon and Grace, 2008).

The endocannabinoid (eCB) system has recently emerged as a promising therapeutic target for the treatment of stressrelated emotional disorders. Generally, facilitation of eCB signaling promotes antidepressant- and anxiolytic-like responses in preclinical animal models, while disruption of this system profoundly affects emotion, cognition, and neuroendocrine functioning (Abush and Akirav, 2010, 2013; Bortolato et al, 2007; Ganon-Elazar and Akirav, 2009, 2012, 2013; Hill et al, 2010; Lutz, 2009; Marsicano et al, 2002; Patel et al, 2004; Ramot and Akirav, 2012; Viveros et al, 2005).

Recent data suggest that the $\mathrm{eCB}$ system could represent a new therapeutic target for the treatment of depression (Bortolato et al, 2007; Hill and Gorzalka, 2005; Macrì and Laviola, 2004). CB1-knockout mice show altered hypothalamic-pituitary-adrenal (HPA) axis function and a higher tendency to exhibit depressive-like responses in the chronic unpredictable mild stress procedure (Martin et al, 2002). These characteristics together with their heightened anxiety (Haller et al, 2002) and deficits in extinction of aversive memories (Marsicano et al, 2002) have been proposed to be analogous to certain symptoms of melancholic depression (Hill and Gorzalka, 2005). Moreover, several cannabinoid compounds have been evaluated in the forced swim test (FST), a widely used screening test for antidepressant potential of novel compounds. In the rat FST, administration of the eCB uptake inhibitor AM404 and the potent $\mathrm{CB} 1$ receptor agonist HU-210 induced decreases in immobility (indicative of antidepressant activity) that were blocked by pretreatment with the $\mathrm{CB1}$ receptor antagonist AM251 (Hill and Gorzalka, 2005).

We have recently suggested that cannabinoid receptor activation, using the CB1/2 receptor agonist WIN55,212-2, could represent a novel approach to the treatment of cognitive deficits that accompany a variety of stress-related neuropsychiatric disorders (Abush and Akirav, 2013). We found that chronic WIN55,212-2 administration in proximity to chronic (ie, 2 weeks) restraint stress prevented the stress-induced impairment in LTP in the vSub-NAc pathway and performance in a non-aversive spatial task (Abush and Akirav, 2013). In that study (Abush and Akirav, 2013), chronic restraint stress did not result in 'classic' depressionlike symptoms such as alterations in anhedonia and coping with stress behavior, and the drug treatment was applied throughout the 2 weeks of the stress period at a high dose (1.2 mg/kg).

Studies indicate a bidirectional, functional relationship between glucocorticoids and eCBs (for a review, see: Akirav, 2013). ECBs have a key role in regulating the HPA axis under basal and stressful conditions (Ganon-Elazar and Akirav, 2009, 2012, 2013; Hill et al, 2009; Patel et al, 2004). On the other hand, stress and glucocorticoids can trigger eCB synthesis and $\mathrm{CB} 1$ receptors signaling to constrain HPA axis activity under acute conditions (Hill et al, 2011; Rademacher et al, 2008). We have recently found that WIN55,212-2 can prevent the impairing effects of an acute stressful experience on contextual extinction in a rat model for post-traumatic stress disorder and that these ameliorating effects of WIN55,212-2 on extinction were mediated by glucocorticoid receptors (GRs) in the basolateral amygdala (BLA) and hippocampus (Ganon-Elazar and Akirav, 2013).

In the current study, we aimed to examine whether 3 days of treatment with WIN55,212-2 $(0.5 \mathrm{mg} / \mathrm{kg})$ could ameliorate the effects of CMS on emotional learning (ie, conditioned avoidance and extinction), LTP in the vSubNAc pathway, and depression-like symptoms (ie, coping with stress strategies, anhedonia, and weight gain). As our previous results suggest that the preventing effects of WIN55,212-2 on extinction after an intense acute stressor are mediated by CB1 and GRs (Ganon-Elazar and Akirav, 2012, 2013), here we examined whether the preventing effects of WIN55,212-2 after CMS exposure are also mediated by $\mathrm{CB} 1$ and GRs.

\section{MATERIALS AND METHODS}

\section{Animals}

Male Sprague-Dawley rats (45-days old), caged individually at $22 \pm 2{ }^{\circ} \mathrm{C}$ under 12 -h light/dark cycles (lights turned on at 0700 hours). Rats had access to water and laboratory rodent chow ad libitum, except when the CMS procedure required deprivation. The experiments were approved by the University of Haifa Ethics and Animal Care Committee, and adequate measures were taken to minimize pain or discomfort.

\section{CMS Protocol}

Rats were subjected to handling or 21 days of mild stressors. The procedure included the following: $18 \mathrm{~h}$ of food deprivation followed by $1.5 \mathrm{~h}$ of limited food access $(0.2 \mathrm{~g}$ pellet), $21 \mathrm{~h}$ of wet cage $(300 \mathrm{ml}$ of water added per $100 \mathrm{~g}$ of bedding), 18 or $21 \mathrm{~h}$ of water deprivation followed by $1.5 \mathrm{~h}$ of empty bottle exposure, $2 \mathrm{~h}$ of paired caging, $3 \mathrm{~h}$ of $45^{\circ}$ cage tilting, or $36 \mathrm{~h}$ of continuous lighting (based on Grønli et al, 2004 with modifications). This schedule of stressors was applied for a 1-week period and repeated over 3 weeks (see Table 1).

\section{Drug Treatment}

The CB1/2 receptor agonist WIN55,212-2 (WIN; IP: $0.5 \mathrm{mg} /$ $\mathrm{kg}$; intra-BLA: $5 \mu \mathrm{g} / \mathrm{side}$ ) or the $\mathrm{CB} 1$ receptor antagonist AM251 (AM; IP: $0.3 \mathrm{mg} / \mathrm{kg}$ ), or the GR antagonist RU-38486 (RU; IP:10 mg/kg) were initially dissolved in dimethylsulfoxide (DMSO) and further diluted with $1 \%$ Tween 80 and $98 \%$ saline $(0.9 \% \mathrm{NaCl})$. Final DMSO concentration was $1 \%$. This DMSO and saline solution was also used as the vehicle. All drugs were from Cayman Chemicals.

Drug concentrations were based on previous results (Abush and Akirav, 2010, 2013; Ganon-Elazar and Akirav, 2009, 2012, 2013; Wulsin et al, 2010). No stress was applied for $4 \mathrm{~h}$ before and after the injection. 
Table I The Chronic Mild Stress (CMS) Protocol

\begin{tabular}{|c|c|c|c|c|c|c|c|}
\hline & Sunday & Monday & Tuesday & Wednesday & Thursday & Friday & Saturday \\
\hline 0700 & & Oi, $36 \mathrm{~h}$ & & & & & \\
\hline 0800 & & & & & & & Eb, $1.5 \mathrm{~h}$ \\
\hline 1000 & & $\mathrm{Fr}, 1.5 \mathrm{~h}$ & & & Eb, $1.5 \mathrm{~h}$ & & \\
\hline 1100 & & & & Til, $3 \mathrm{~h}$ & & & \\
\hline 1200 & & & & & $\mathrm{Ph}, 2 \mathrm{~h}$ & & \\
\hline \multicolumn{8}{|l|}{1400} \\
\hline 1600 & $\mathrm{Fd}, 18 \mathrm{~h}$ & & & & & & \\
\hline 1700 & & & Wet, 2 I h & & & & \\
\hline 1800 & & & & Wd, $18 \mathrm{~h}$ & & & \\
\hline
\end{tabular}

Abbreviations: Eb, exposure to empty bottle; Fd, food deprivation; Fr, food restriction; Oi, overnight illumination; Ph, paired housing; Til, tilted cage;

Wd, water deprivation; Wet, wet cage.

\section{Cannulation and Drug Microinjection}

Rats were anesthetized with $4.8 \mathrm{ml} / \mathrm{kg}$ Equithesin, restrained in a stereotactic apparatus, and implanted bilaterally with a stainless steel guide cannula (23-gauge, thin wall) aimed at the BLA (anteroposterior, $-5 \mathrm{~mm}$; lateral, $\pm 3 \mathrm{~mm}$; ventral, $-6.7 \mathrm{~mm}$ ). The cannula was positioned in place with acrylic dental cement and secured by two skull screws. A stylus was placed in the guide cannula to prevent clogging. Animals were allowed 1 week to recuperate before being subjected to experimental manipulations. For microinjection, the stylus was removed from the guide cannula, and a 28-gauge injection cannula, extending $1.0 \mathrm{~mm}$ from the tip of the guide cannula, was inserted. The injection cannula was connected via PE20 tubing to a Hamilton microsyringe driven by a microinfusion pump. Microinjection was performed bilaterally with a $0.5-\mu l$ volume per side delivered over $1 \mathrm{~min}$.

\section{Inhibitory Avoidance (IA)}

Animals were placed in an IA apparatus with a metal grid floor (Ganon-Elazar and Akirav, 2009, 2012). The apparatus was divided into a light side and a dark side, and the rats were placed in the light side, facing the left rear corner of the box.

For conditioning (Cond), when the rats crossed over to the dark side of the box (with four paws on the grid), the opening between the two sides of the box was blocked and they received a 2-s, $0.8-\mathrm{mA}$ scrambled footshock. After administration of the footshock, the rats remained in the dark side for an additional $60 \mathrm{~s}$, after which they were returned back to the home cage.

For extinction, rats were submitted to a non-reinforced test trial every $24 \mathrm{~h}$ for 5 days (Ext1-Ext5), beginning $24 \mathrm{~h}$ after conditioning. The first extinction trial also indicated fear retrieval (Ret/Ext1). Each rat was placed in the light side of the box, and the time elapsed until it crossed over to the dark side (ie, latency) was measured. If, after $180 \mathrm{~s}$, the rat did not cross over on its own, the experimenter gently guided it to the dark side. The opening between the two sides of the shuttle was then blocked, no footshock was administered, and the rat was allowed to explore the dark side freely for $180 \mathrm{~s}$, after which it was returned back to the home cage.

\section{Electrophysiology}

Rats were anesthetized (with 40\% urethane, 5\% chloral hydrate in saline, injection volume of $4 \mathrm{ml} / 1 \mathrm{~kg}$, IP) and placed in a stereotaxic frame. Small burr holes were drilled in the skull to allow electrodes to be inserted into the brain. A recording microelectrode (glass, tip diameter of $2-5 \mu \mathrm{m}$, filled with $2 \mathrm{M} \mathrm{NaCl}$, resistance of 1-4 M ohm) was inserted into the NAc shell (anteroposterior, $+1.6 \mathrm{~mm}$; lateral, $\pm 1.0 \mathrm{~mm}$; ventral, $-5.5 \mathrm{~mm}$ ). A bipolar $125-\mu \mathrm{m}$ stimulating electrode was positioned in the vSub (anteroposterior, $-6.5 \mathrm{~mm}$; lateral, $\pm 5.0 \mathrm{~mm}$; ventral, $-6.0 \mathrm{~mm}$ ). After positioning the electrodes, the rat was left for $60 \mathrm{~min}$ before commencing the experiment.

LTP was induced by theta-like high-frequency stimulation (HFS; three sets of 10 trains; each train consisting of 10 pulses at $200 \mathrm{~Hz}$; inter-train interval, $200 \mathrm{~ms}$; inter-set interval, $1 \mathrm{~min}$ ) to the vSub. Field potentials were recorded from the NAc every $5 \mathrm{~min}$ for $60 \mathrm{~min}$ after HFS to the vSub. LTP was measured as an increase in the amplitude and slope of the evoked field potentials. Potentiation was measured as a percentage of change from the average of the $30 \mathrm{~min}$ baseline before HFS (Abush and Akirav, 2013). The amplitude was measured by peak-to-peak values based on the previous findings of LTP in the vSub-NAc pathway (Abush and Akirav, 2012; Dong et al, 2007). However, it is the slope that is considered to reflect LTP (ie, the strengthening of existing synaptic contacts), whereas the amplitude may also reflect the activity of the cells (Abush and Akirav, 2013).

\section{FST}

A cylindrical water container made from dark nontransparent plastic $(62 \mathrm{~cm}$ diameter, $40 \mathrm{~cm}$ height, filled with water at temperature of $24^{\circ} \mathrm{C}$ ). The water level was such that the rat could not touch the bottom with its hind paws. Rats were exposed to the swim tank for $15 \mathrm{~min}$ on the first day (pre-test) and $5 \mathrm{~min}$ on the second day (test). Video films of the second day of each FST session were 
analyzed for passive coping (immobility) or active coping (climbing and swimming) strategies. After each session, water in the cylinders was emptied and replaced with fresh water for the next subject (Abush and Akirav, 2013).

\section{Sucrose Intake}

Water bottles were removed before the dark part of the cycle and replaced with bottles containing a 1\% sucrose solution. Sucrose consumption was measured during the 12-dark hours of the cycle and was then normalized according to every rat's specific weight. Measurements of sucrose consumption were taken once a week, on days 0 (baseline), 7, 14, 21, and 28 (Abush and Akirav, 2013).

\section{Weight Monitoring}

The weight of all animals was monitored once a week, on days 0 (baseline), $7,14,21$, and 28 . Body weight change is presented as the cumulative percentage from baseline.

\section{Statistical Analysis}

The results are expressed as means \pm SEM. For statistical analysis, mixed-design ANOVA or one-way ANOVA were used. All post hoc comparisons were made using the least significant difference multiple-comparison test (LSD).

\section{Research Plan}

Each test, except for the sucrose intake and weight gain, was performed on different sets of rats to prevent carryover effects due to multiple tests.

1. Emotional learning (IA): CMS or handling on days 1-21. Vehicle (Veh), WIN, or AM + WIN IP on days 19-21. IA conditioning was tested on day 23 (Figure 1a) or day 28 (Figure 1b). To examine the effects of the drugs on IA without exposure to CMS, rats were injected with Vehicle, WIN, or AM on days 1-3 and tested for IA conditioning on day 5 (Figure 1c) or day 10 (Figure 1d). To test for GR involvement, CMS or handling on days 1-21. Vehicle (Veh), RU, or RU + WIN IP on days 19-21. IA conditioning was tested on day 23 (Figure 1e).

2. LTP: CMS or handling on days 1-21. Vehicle, WIN, or AM + WIN IP on days 19-21. LTP was measured on day 23 (Figure $2 \mathrm{a}$ and $\mathrm{b}$ ) or day 28 (Figure $2 \mathrm{c}$ and d). To test for GR involvement, CMS or handling on days 1-21. Vehicle (Veh), RU, or RU + WIN IP on days 19-21. LTP was measured on day 23 (Figure $3 \mathrm{a}$ and b). To examine the effects of the drugs on LTP without exposure to CMS, rats were injected with Vehicle, WIN, AM, or RU on days $1-3$ and tested for LTP on day 5 (Figure $3 \mathrm{c}$ and $\mathrm{d}$ ).

3. FST: CMS or handling on days 1-21. Vehicle or WIN IP on days 19-21. Coping behavior was measured on day 23 (Figure 4a) or day 28 (Figure 4d). In another experiment, rats were exposed to CMS on days 1-21 and to intra-BLA WIN55,212-2 immediately after the pre-test on day 22 (Figure 4b). To test the effects of systemic WIN55,212-2 on FST without CMS exposure, rats were injected with vehicle or WIN55,212-2 IP immediately after the pre-test on day 1 (Figure $4 \mathrm{e}$ ).
4. Anhedonia and weight gain: CMS or handling on days 1-21. Vehicle or WIN IP on days 19-21. Sucrose intake (Figure 5a) and weight gain (Figure 5b) were measured once a week on days 0 (baseline), 7, 14, 21, and 28.

\section{RESULTS}

\section{The Effects of CMS and WIN55,212-2 on Conditioned Avoidance and Extinction}

First, we examined the effects of CMS exposure on conditioned avoidance and extinction. As WIN55,212-2 is a CB1/CB2 agonist, we also examined whether the preventing effects of WIN55,212-2 on avoidance after CMS are mediated by the $\mathrm{CB} 1$ receptor by using a combination of WIN55,212-2 and the CB1 receptor antagonist AM251 (Abush and Akirav, 2013).

When conditioned avoidance behavior was tested on day 23, mixed-design ANOVA for group $\times$ days $(4 \times 6)$ on the latency to enter the dark side revealed a significant difference between the groups $\left(\mathrm{F}_{(3,40)}=10.2, p<0.001\right)$, the days $\left(\mathrm{F}_{(1,40)}=6.42, p<0.05\right)$, and a significant interaction effect $\left(\mathrm{F}_{(3,40)}=9.49, p<0.001\right)$ (Figure 1a).

Post hoc comparison revealed that on Ret/Ext1, the No CMS-Veh group demonstrated decreased latency compared with all the groups (CMS-Veh and CMS-AM+WIN: $p<0.01$; CMS-WIN: $p<0.05$ ). On Ext2, Ext3, and Ext4, the No CMS-Veh and CMS-WIN groups demonstrated decreased latency compared with the CMS-Veh and CMS$\mathrm{AM}+$ WIN groups (Ext2: CMS-Veh: $p<0.01$; CMS-AM + WIN: $p<0.05$; Ext3-4: $p<0.01$ ). On Ext5, the No CMS-Veh group demonstrated decreased latency compared with the CMS-Veh and CMS-AM + WIN groups $(p<0.01)$. Hence, CMS impaired extinction, and WIN55,212-2 prevented this impairment. The preventing effect of WIN55,212-2 after CMS was mediated via CB1 receptors as rats co-administered with AM251 and WIN after CMS behaved in a similar manner to the CMS vehicle group.

When conditioned avoidance behavior was tested on day 28, mixed-design ANOVA for group $\times$ days $(4 \times 6)$ on the latency to enter the dark side revealed a significant difference between the groups $\left(\mathrm{F}_{(3,32)}=8.815, p<0.001\right)$ and a significant interaction effect $\left(\mathrm{F}_{(3,32)}=8.483\right.$, $p<0.001)$, with no effect on days $\left(\mathrm{F}_{(1,32)}<1\right.$, NS) (Figure 1b). Post hoc comparison revealed that on Ext1, the CMS-WIN group demonstrated decreased latency compared with the CMS-Veh $(p<0.01)$ and CMS-AM + WIN group $(p=0.05)$. On Ext2, the No CMS-Veh group demonstrated decreased latency compared with the CMSVeh group $(p<0.05)$. On Ext3, Ext4, and Ext5, the No CMSVeh and CMS-WIN groups demonstrated decreased latency compared with the CMS-Veh $(p<0.01)$ and CMS-AM + WIN (Ext 3: $p<0.05$; Ext4 and Ext5: $p<0.001$ ) groups. Hence, the effects of CMS and WIN55,212-2 on extinction were observed even 1 week after the last stress exposure and the last injection.

To examine the effects of the drugs on extinction without exposure to CMS, rats were injected with Vehicle, WIN, or AM251 on days 1-3 and tested for IA conditioning on day 5 (Figure 1c; equivalent to testing conditioning on day 23 in Figure 1a, after the drugs were injected on days 19-21) or 
a

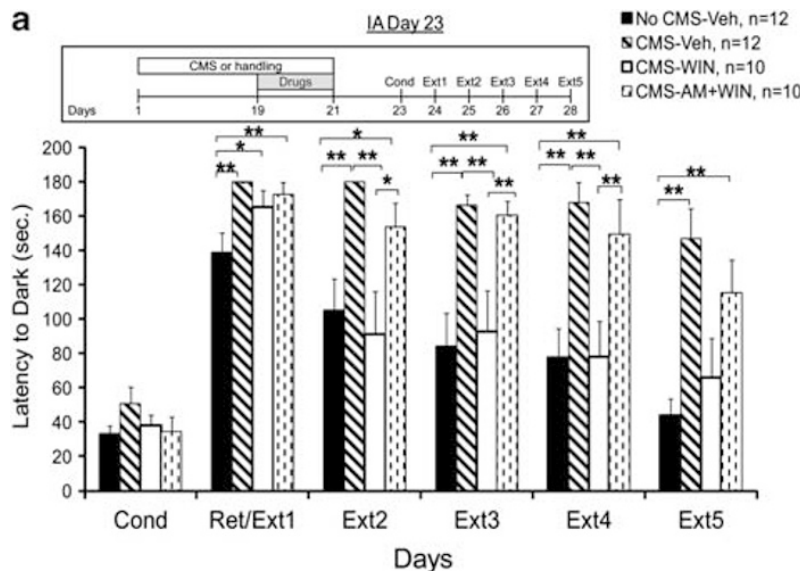

C

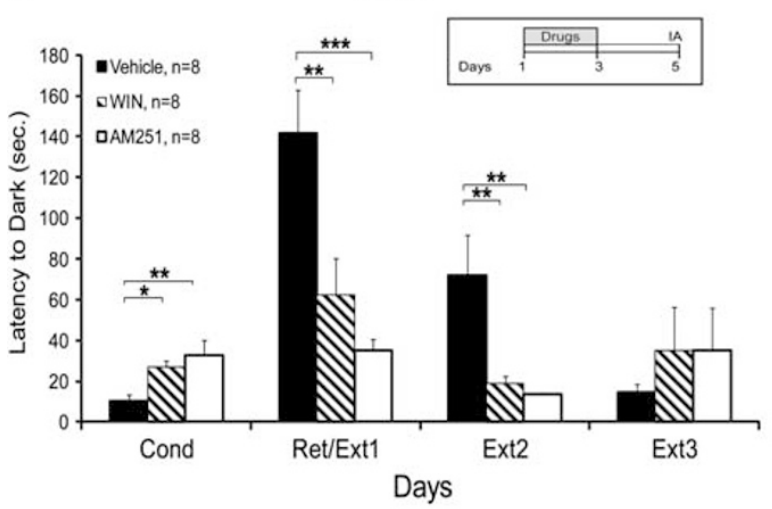

b
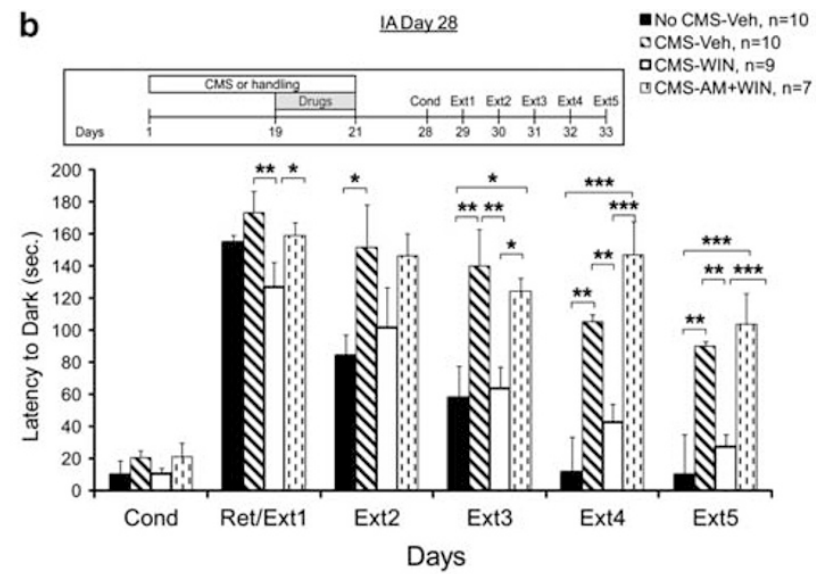

d

IADay 10
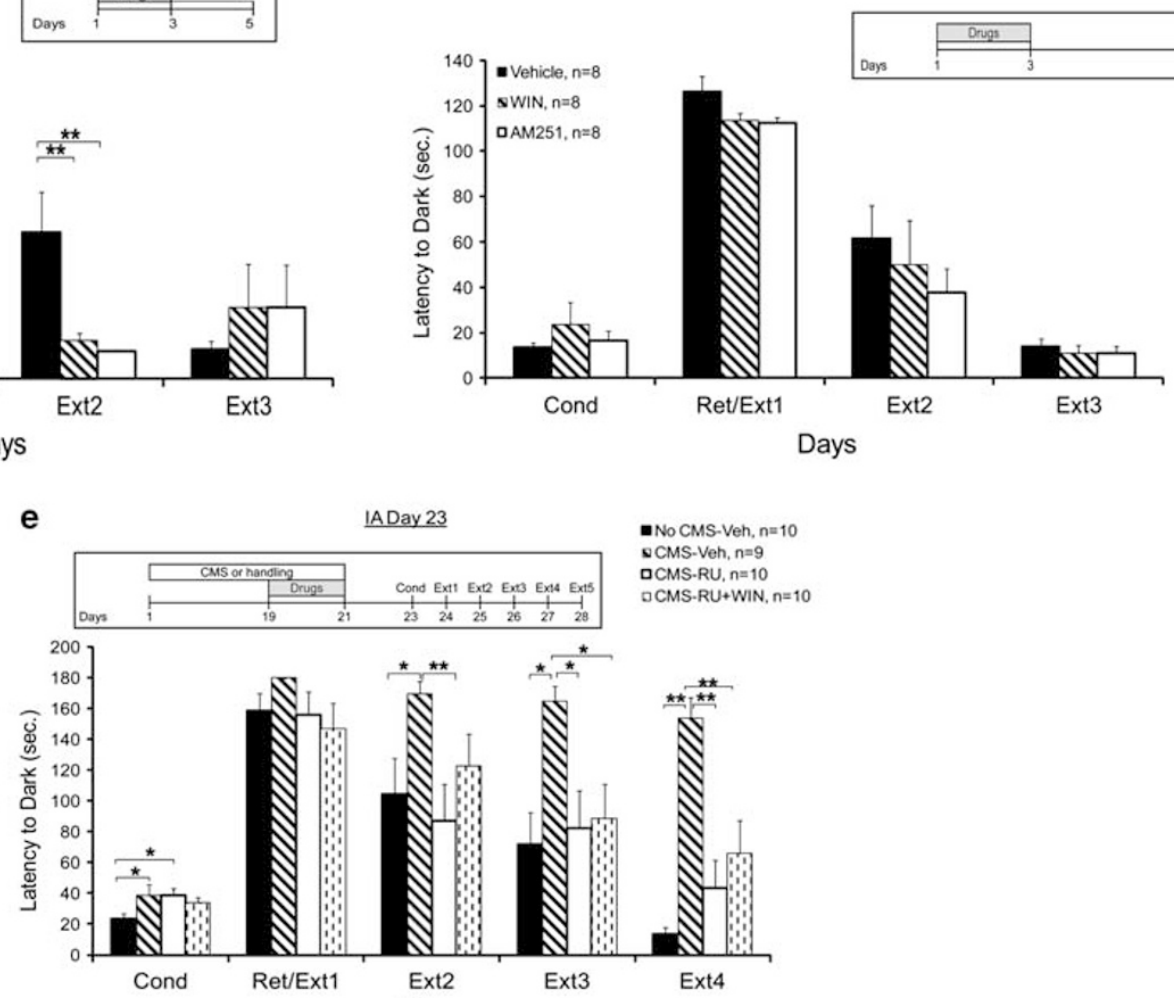

Figure I WIN55,212-2 prevents the CMS-induced impairment in extinction. (a) When tested on day 23, the No CMS-Veh group demonstrated decreased latency compared with all the groups on ExtI. On Ext2, Ext3, and Ext4, the No CMS-Veh and CMS-WIN groups demonstrated decreased latency compared with the CMS-Veh and CMS-WIN + AM groups. On Ext5, the No CMS + Veh group demonstrated decreased latency compared with the CMS + Veh and CMS + WIN + AM groups (*p<0.05; *** $<0.01$ ). (b) When tested on day 28, the CMS-WIN group demonstrated decreased latency compared with the CMS-Veh and CMS + WIN + AM group on Extl. On Ext2, the No CMS + Veh group demonstrated decreased latency compared with the CMS-Veh. On Ext3, Ext4, and Ext5, the No CMS + Veh and CMS + WIN groups demonstrated decreased latency compared with the CMS-Veh and $C M S+W I N+$ AM groups ( ${ }^{*} p<0.05$; ${ }^{*} * p<0.01$; **** $<0.00$ I). (c) When the drugs were injected with no stress exposure 2 days before conditioning, the Vehicle group demonstrated decreased latency compared with the other groups on Cond and increased latency on ExtI and Ext2 (* $p<0.05$; $* * * 0.01$; **** $p<0.00$ I). (d) When WIN55,2 I2-2 or AM25 I were injected without stress exposure a week before conditioning, conditioned avoidance and extinction levels were not significantly different from the vehicle-treated rats. (e) When tested on day 23, the No CMS-Veh group demonstrated decreased latency compared with the CMS-Veh and CMS-RU groups on Cond. On Ext2, the CMS-Veh group demonstrated increased latency compared with the No CMSVeh and CMS-RU groups. On Ext3 and Ext4, the CMS-Veh group demonstrated increased latency compared with all the groups (*p<0.05; ** $p<0.0 \mathrm{I})$.

day 10 (Figure 1d; equivalent to testing conditioning on day 28 in Figure $1 \mathrm{~b}$, after the drugs were injected on days 19-21).

When conditioned avoidance was tested on day 5 (Figure 1c), mixed-design ANOVA on the latency to enter the dark side revealed a significant effect for group $\left(\mathrm{F}_{(2,21)}=3.444, p=0.05\right)$ but not for days $\left(\mathrm{F}_{(1,21)}=1.41\right.$, NS) or the interaction between group and days $\left(\mathrm{F}_{(2,21)}<1\right.$, NS). Post hoc comparison revealed that the Vehicle group demonstrated decreased latency compared with the other 

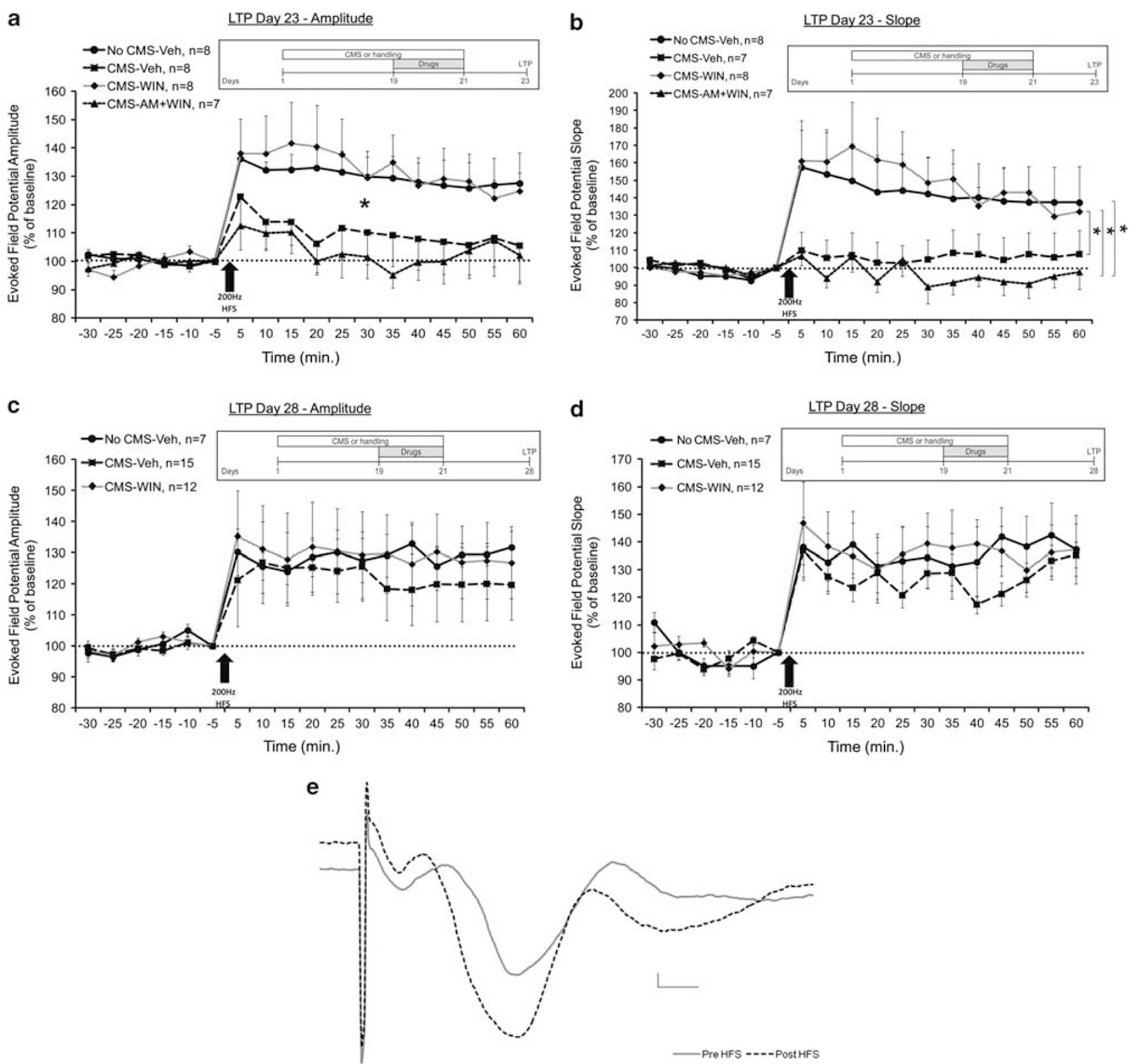

Figure 2 WIN55,2I 2-2 prevents the CMS-induced impairment in LTP in the vSub-NAc pathway. (a) When tested on day 23, the CMS-Veh and CMS$A M+$ WIN groups demonstrated significantly reduced amplitude compared with the No CMS-Veh and CMS-WIN groups post HFS (* $p<0.05$ ). (b) When tested on day 23, the CMS-Veh and CMS-AM+WIN groups demonstrated significantly reduced slope compared with the CMS-WIN group post HFS. Also the CMS-WIN + AM showed reduced slope compared with the No CMS-Veh group post HFS (*p<0.05). (c) When tested on day 28, all the groups demonstrated similar amplitude, suggesting intact LTP. (d) When tested on day 28, all the groups demonstrated similar slope, suggesting intact LTP. (e) Representative traces in the NAc taken before (continuous line) and I h after (broken line) HFS to the vSub (calibration: $0.2 \mathrm{mV}, 10 \mathrm{msec}$ ).

groups on Cond (WIN: $p<0.05$; AM: $p<0.01$ ) and increased latency on Ext1 (WIN: $p<0.01$; AM: $p<0.001$ ) and Ext 2 (WIN and AM: $p<0.01$ ). Hence, when WIN55,212-2 or AM251 were injected without stress exposure 2 days before IA, rats showed impaired fear retrieval (Figure 1c).

However, when the drugs were injected during the last days of the CMS procedure, they had no effect on fear retrieval (see Figure 1a) as the CMS-WIN group showed increased latency compared with the No CMS-Vehicle group on Ret/Ext1.

When conditioned avoidance was tested on day 10 (Figure 1d), mixed-design ANOVA on the latency to enter the dark side did not reveal a significant effect for group
$\left(\mathrm{F}_{(2,21)}<1, \mathrm{NS}\right)$ or the interaction between group and days $\left(\mathrm{F}_{(2,21)}<1\right.$, NS). A significant effect was found for days $\left.\mathrm{F}_{(1,21)}=10.506, p<0.01\right)$. Hence, when WIN55,212-2 or AM251 were injected without stress exposure a week before IA, conditioned avoidance and extinction levels were not significantly different from vehicle-treated rats. A possible explanation for the different effects of WIN55,212-2 and AM251 on avoidance when administered a week before training could be that cannabinoids have delayed effects on acquisition of the avoidance memory.

Although the drugs impaired fear retrieval when administered 2 days, but not 7 days, before conditioning, WIN55,212-2 prevented the CMS-induced impairment in extinction on both occasions. 
a

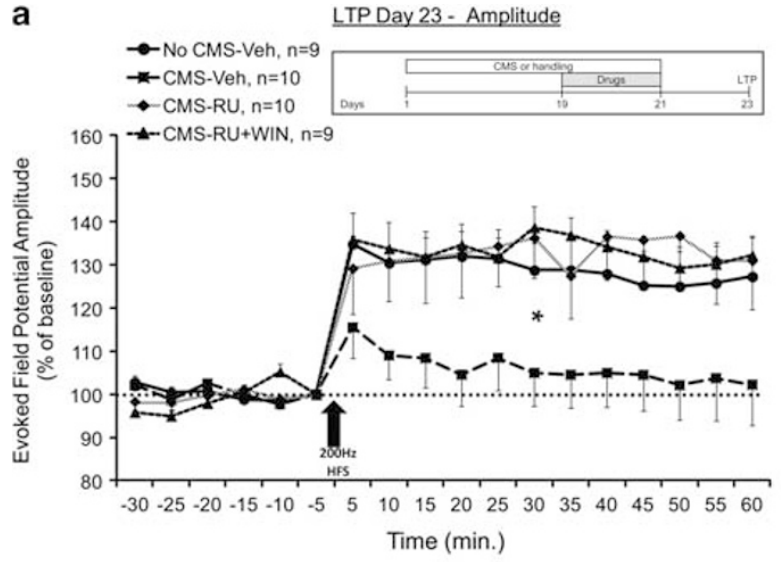

C

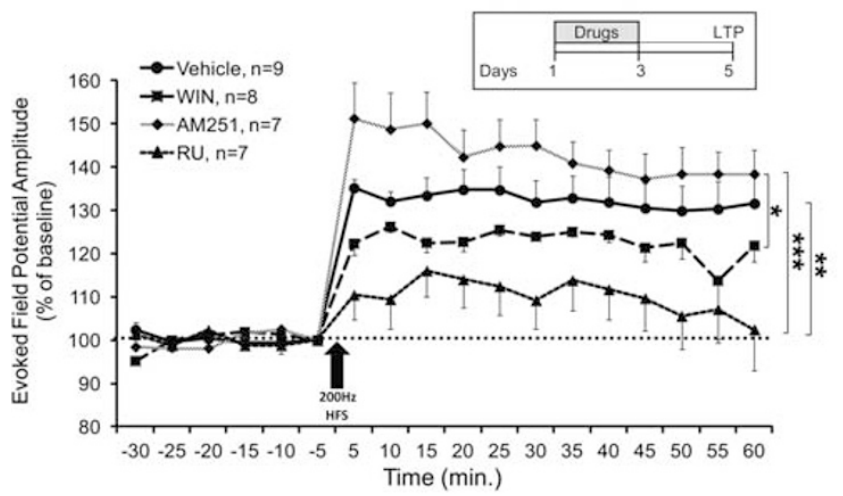

b

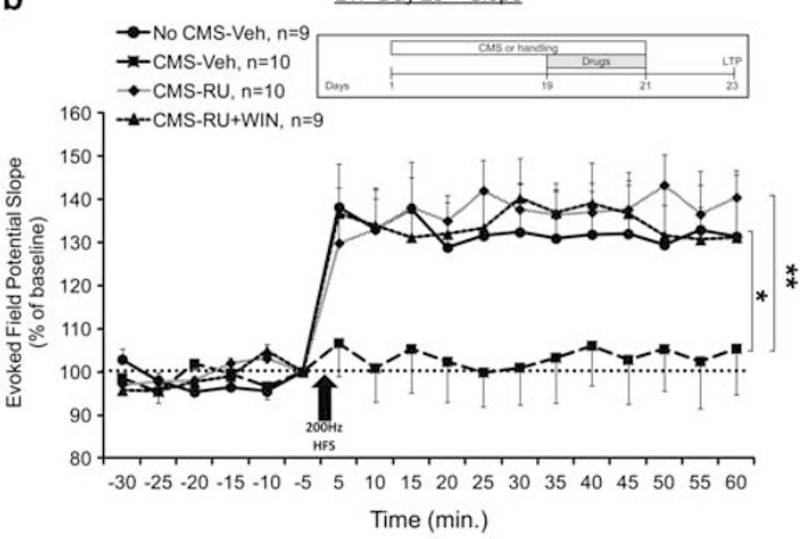

d

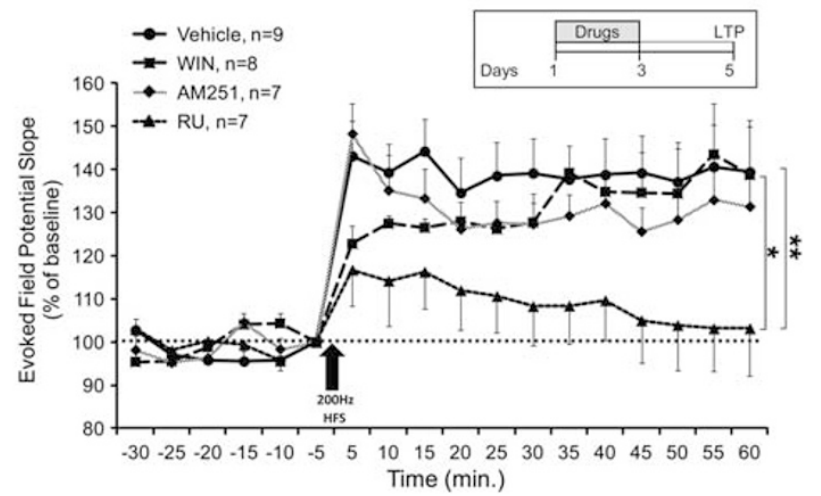

Figure 3 RU-38486 prevents the CMS-induced impairment in LTP in the vSub-NAc pathway. (a) When tested on day 23, the CMS-Veh group demonstrated significantly reduced amplitude compared with all groups post HFS $(* p<0.05)$. (b) When tested on day 23 , the CMS-Veh group demonstrated significantly reduced slope compared with all the groups post HFS (*p $<0.05$; ** $p<0.01$ ). (c) When the drugs were injected without stress exposure, the RU group demonstrated reduced amplitude compared with the Vehicle and AM groups, and the WIN group demonstrated reduced amplitude compared with the AM group ( ${ }^{*} p<0.05$; ** $p<0.0$ I; **** $p<0.00 \mathrm{I}$ ). (d) When the drugs were injected without stress exposure, the RU group demonstrated reduced slope compared with the Vehicle and WIN groups $(* p<0.05$; $* * 0<0.0$ ).

Studies indicate a bidirectional, functional relationship between glucocorticoids and the eCB system (Akirav, 2013). It has been suggested that glucocorticoids recruit eCB signaling in the BLA and hippocampus to modulate aversive memory consolidation (Atsak et al, 2012; Campolongo et al, 2009). Moreover, de Bitencourt et al (2013) suggested that eCBs are recruited by glucocorticoids in the process of extinction of aversive memories.

We have recently found that GRs in the BLA and hippocampus mediate the preventive effects of WIN55,212-2 on contextual extinction after an acute stressful experience. Hence, here we aimed to examine whether GRs also mediate the preventive effects of WIN55,212-2 on avoidance extinction in a rat model of depression. To that end, we examined the effects of the GR antagonist RU-38486 on avoidance after CMS and used a combination of RU-38486 and WIN55,212-2 to examine whether the antagonist would block the preventing effects of WIN55,212-2 on extinction.

When conditioned avoidance behavior was tested on day 23, mixed-design ANOVA for group $\times$ days $(4 \times 5)$ on the latency to enter the dark side revealed a significant difference between the groups $\left(\mathrm{F}_{(3,35)}=7.309, p<0.001\right)$ and a significant interaction effect $\left(\mathrm{F}_{(3,35)}=9.361\right.$, $p<0.001)$, with no effect on days $\left(F_{(1,35)}<1\right.$, NS) (Figure 1e).

Post hoc comparison revealed that on Cond, the No CMSVeh group demonstrated decreased latency compared with the CMS-Veh and CMS-RU groups $(p<0.05)$. On Ext2, the CMS-Veh group demonstrated increased latency compared with the No CMS-Veh $(p<0.05)$ and CMS-RU $(p<0.01)$ groups. On Ext3 and Ext4, the CMS-Veh group demonstrated increased latency compared with all the groups (Ext3: $p<0.05$; Ext4: $p<0.01$ ). Hence, the GR antagonist also prevented the effects of CMS on extinction and when co-administered with WIN55,212-2, the preventive effect on extinction was maintained. This suggests that the preventing effects of WIN55,212-2 on extinction after CMS are not mediated by GRs. A higher dose of RU $(20 \mathrm{mg} / \mathrm{kg})$ had a similar effect of preventing the effects of CMS on extinction with or without co-administering WIN55,212-2 (data not shown).

\section{The Effects of CMS and WIN55,212-2 on Synaptic Plasticity in the vSub-Nac Pathway}

When synaptic plasticity in the vSub-Nac pathway was tested on day 23, mixed-design ANOVA on amplitude 
a

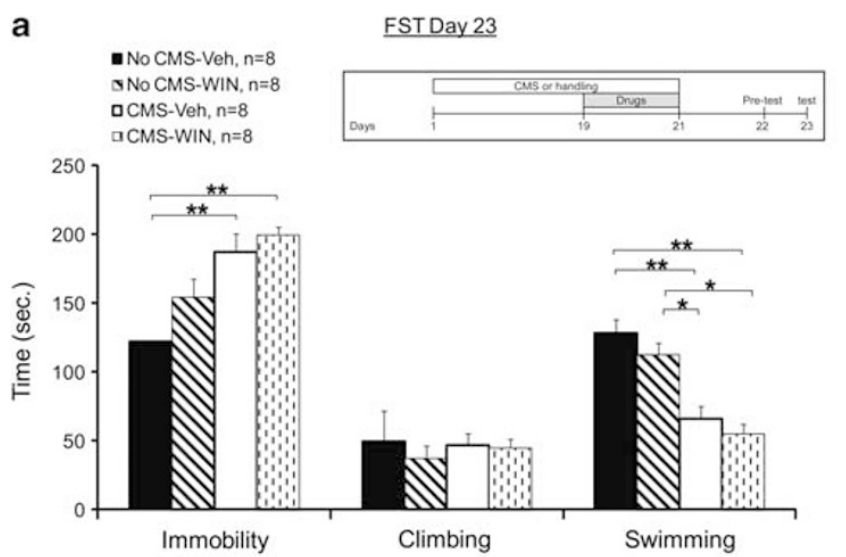

C

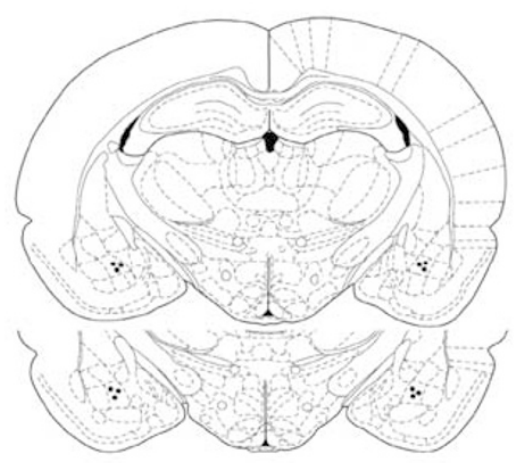

e $\quad$ FSTPre-test b

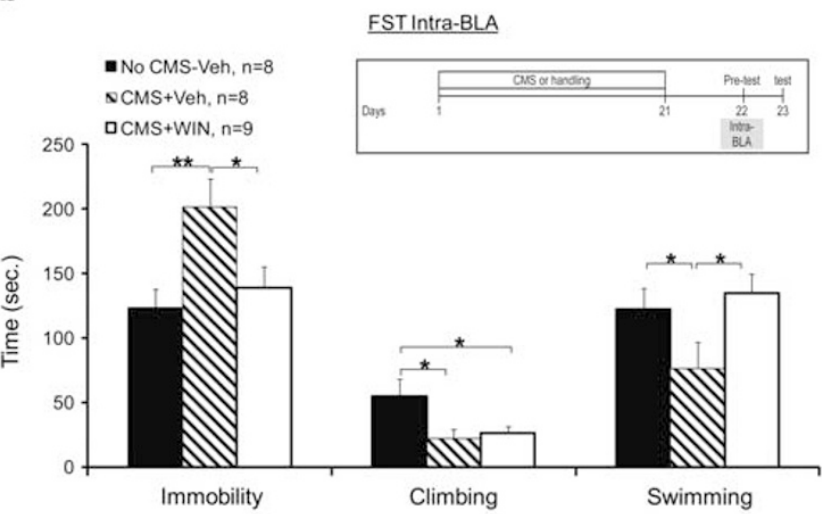

d

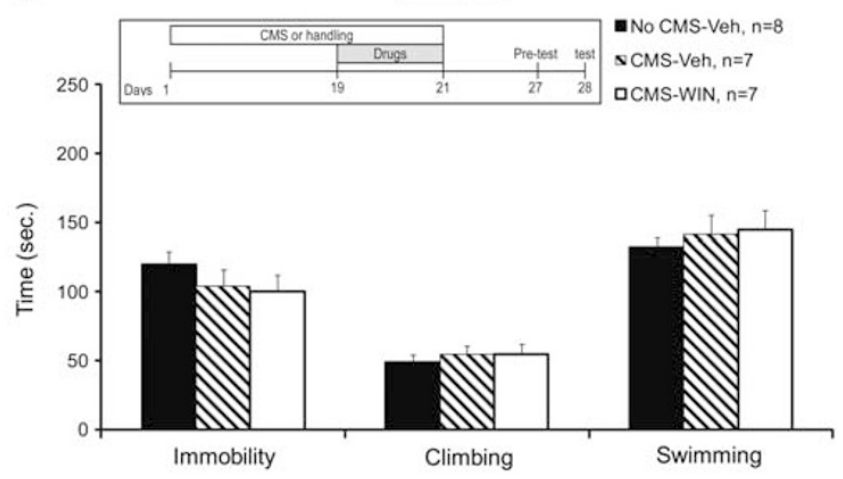

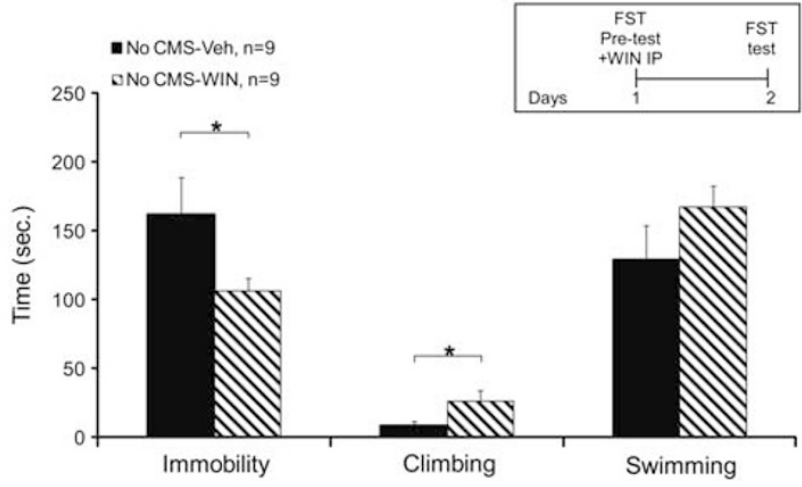

Figure 4 The effects of CMS and WIN55,2I2-2 on stress-coping behavior in the forced swim test. (a) When tested on day 23, the No CMS-Veh group demonstrated less immobility compared with the CMS-Veh and CMS-WIN groups. Also, the No CMS-Veh and No CMS-WIN groups demonstrated more swimming compared with the CMS-Veh and CMS-WIN groups $\left(* p<0.05\right.$; ${ }^{*} p<0.01$ ). (b) When microinjected into the BLA, the CMS-Veh group demonstrated increased immobility and reduced swimming compared with the No CMS-Veh and CMS-WIN groups. Also, the No CMS-Veh group demonstrated more climbing compared with the CMS-Veh and CMS-WIN groups $(* p<0.05 ; * * p<0.01$ ). (c) Representative schematic drawings of cannulae tip positions in the BLA. A coronal view at position 3.14 and $3.30 \mathrm{~mm}$ posterior to bregma. (d) When coping behavior was tested on day 28 , there were no differences between the groups in immobility, climbing, or swimming. (e) When WIN was injected systemically after pretest with no CMS exposure, the WIN group demonstrated less immobility and more climbing than the Vehicle group $(* p<0.05)$.

(Figure 2a) and slope (Figure $2 \mathrm{~b}$ ) post HFS (group $\times$ time $(4 \times 12))$ revealed a significant effect for group (amplitude: $\mathrm{F}_{(3,26)}=3.341, p<0.05$; slope: $\left.\mathrm{F}_{(3,26)}=3.149, p<0.05\right)$, time (amplitude: $F_{(1,26)}=4.392, p<0.05$; slope: $F_{(3,26)}=6.615$, $p<0.05)$ but not the interaction between group and time. Post hoc comparison revealed significantly reduced ampli- tude in the CMS-Veh and the CMS-AM+WIN groups compared with the No CMS-Veh and CMS-WIN groups $(p<0.05)$ and reduced slope in the CMS-AM+WIN and CMS-Veh group compared with the CMS-WIN group $(p<0.05)$. Also the CMS-WIN + AM group showed reduced slope compared with the No CMS-Veh group $(p<0.05)$. 
a

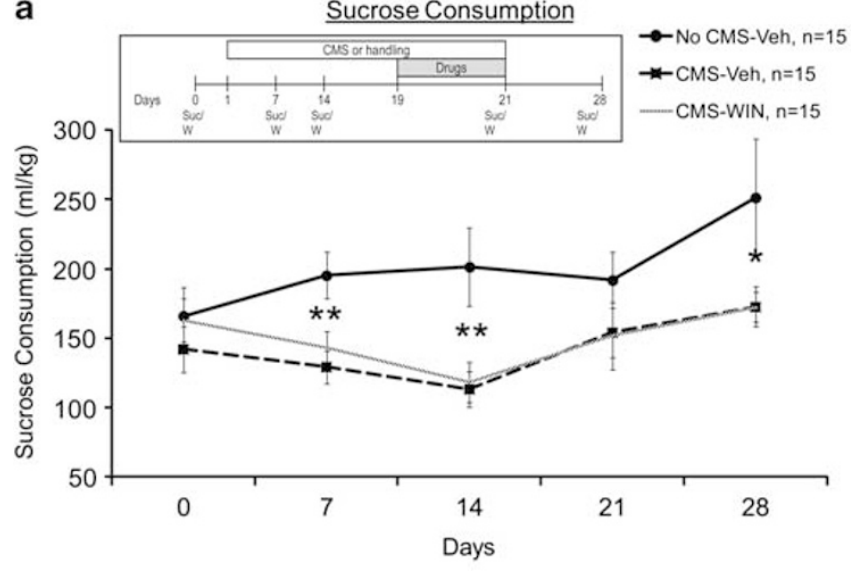

b

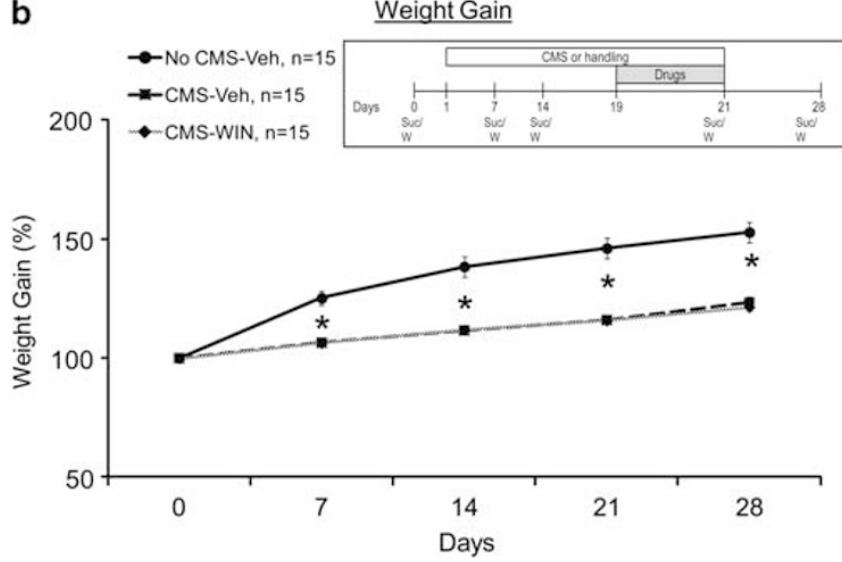

Figure 5 The effects of CMS and WIN55,2 I2-2 on sucrose intake and weight gain. (a) The CMS-Veh and CMS-WIN groups demonstrated reduced sucrose intake compared with the No CMS-Veh group on days 7 , 14 , and $28(* p<0.05$; $* * p<0.01)$. (b) The CMS-Veh and CMS-WIN groups demonstrated lower weight gain compared with the No CMS-Veh group on days $7,14,21$, and 28 ( $* 2<0.05$; averaged baseline weight: $397.37 \pm 33.86)$

This suggests that CMS impairs LTP, that WIN55,212-2 can prevent this impairment, and that the preventing effect is mediated via CB1 receptors.

When synaptic plasticity was tested on day 28 , mixeddesign ANOVA on amplitude (Figure 2c) and slope (Figure $2 \mathrm{~d}$ ) post HFS (group $\times$ time $(3 \times 12))$ did not reveal a significant effect for group (amplitude: $\mathrm{F}_{(2,31)}<1$, NS; slope: $\mathrm{F}_{(2,31)}=1.833$, NS), time (amplitude: $\mathrm{F}_{(1,31)}=3.1, \mathrm{NS}$; slope: $\left.F_{(1,31)}=1.885, \mathrm{NS}\right)$, or the interaction between group and time (amplitude: $\mathrm{F}_{(2,31)}<1, \mathrm{NS} ; \mathrm{F}_{(2,31)}=3.124$, NS). This suggests a significant recovery of LTP in the CMS group 1 week after the stress ended.

We also examined whether GRs mediate the preventive effects of WIN55,212-2 on LTP tested 2 days after CMS. When synaptic plasticity in the vSub-Nac pathway was tested on day 23, mixed-design ANOVA on amplitude (Figure $3 \mathrm{a}$ ) and slope (Figure $3 \mathrm{~b}$ ) post HFS (group $\times$ time $(4 \times 12))$ revealed a significant effect for group (amplitude: $\mathrm{F}_{(3,34)}=3.104, p=0.039$; slope: $\left.\mathrm{F}_{(3,34)}=3.518, p<0.025\right)$ but not for time (amplitude: $\mathrm{F}_{(1,34)}=3.276$, NS; slope: $\mathrm{F}_{(1,34)}<1$, NS) or the interaction between group and time (amplitude: $F_{(3,34)}=1.185$, NS; slope: $F_{(3,34)}<1$, NS).
Post hoc comparison revealed significantly reduced amplitude in the CMS-Veh group compared with the No CMSVeh (amplitude and slope: $p<0.05$ ), CMS-RU (amplitude: $p<0.05$; slope: $p<0.01$ ), and CMS-RU + WIN (amplitude and slope: $p<0.05)$ groups. This suggests that RU-38486 prevented the CMS-induced impairment in LTP, and when co-administered with WIN55,212-2, the preventive effects on LTP after CMS were maintained.

To examine the effects of the drugs on LTP without exposure to CMS, rats were injected with Vehicle, WIN, AM251, or RU on days 1-3 and tested for LTP on day 5 (equivalent to LTP tested on day 23 in Figure 2 a, after the drugs were injected on days 19-21).

When synaptic plasticity in the vSub-Nac pathway was tested on day 5, mixed-design ANOVA on amplitude (Figure 3c) and slope (Figure $3 \mathrm{~d}$ ) post HFS (group $\times$ time $(4 \times 12))$ revealed a significant effect for group (amplitude: $\mathrm{F}_{(3,27)}=6.719, p<0.01$; slope: $\left.\mathrm{F}_{(3,27)}=2.975, p<0.05\right)$, time (amplitude: $\mathrm{F}_{(1,27)}=10.494, p<0.01$ but not slope), and the interaction between group and time (slope: $F_{(1,27)}=3.089$, $p<0.05$ but not amplitude). Post hoc comparison revealed significantly reduced amplitude in the RU group compared with the Vehicle $(p<0.01)$ and AM $(p<0.001)$ groups and reduced amplitude in the WIN group compared with the AM group $(p<0.05)$. The RU group showed reduced slope compared with the Vehicle $(p<0.01)$ and WIN $(p<0.05)$ groups. Hence, RU-38486 by itself, with no stress exposure, impaired LTP tested 2 days after the last injection.

\section{The Effects of CMS and WIN55,212-2 on Stress-Coping Behavior in the FST}

When coping behavior was tested on day 23, one-way ANOVA revealed a significant difference between the groups in immobility $\left(\mathrm{F}_{(3,11)}=4.642, p<0.01\right)$ and swimming $\left(\mathrm{F}_{(3,31)}=6.014, p<0.01\right)$ (Figure $\left.4 \mathrm{a}\right)$. Post hoc comparison revealed that the No CMS-Veh group demonstrated less immobility compared with the CMS-Veh and CMS-WIN groups $(p<0.01)$. Also, the No CMS-Veh $(p<0.01)$ and No CMS-WIN $(p<0.05)$ groups demonstrated more swimming compared with the CMS-Veh and CMS-WIN groups. Hence, CMS caused an increase in passive stress coping and a decrease in active stress coping and the treatment with the agonist WIN55,212-2 did not prevent this effect. Furthermore, WIN55,212-2 by itself (without stress exposure; No CMS-WIN group) had no effect on FST behavior when injected for 3 days on days 19-21 of the experiment.

We have previously demonstrated that intra-BLA WIN55,212-2 can prevent the effects of stress on behavior and physiology (Ganon-Elazar and Akirav, 2009, 2012, 2013; Ramot and Akirav, 2012). Hence, next we examined whether WIN55,212-2 microinjected into the BLA immediately after the pre-test on day 22 would prevent the effects of CMS on coping behavior tested on day 23. The drug was injected specifically into the BLA after the pre-test as previous results from our lab showed that cannabinoid receptor activation in the BLA in proximity to acute stress exposure can prevent the effects of stress on behavior (Ganon-Elazar and Akirav, 2009, 2012).

One-way ANOVA on stress-coping strategy revealed significant differences between the groups in immobility $\left(\mathrm{F}_{(2,22)}=5.236, p<0.05\right)$, climbing $\left(\mathrm{F}_{(2,22)}=3.893, p<0.05\right)$, 
and swimming $\left(\mathrm{F}_{(2,22)}=3.85, p=0.05\right)$ (Figure $\left.4 \mathrm{~b}\right)$. Post hoc comparison revealed that the CMS-Veh group demonstrated increased immobility and reduced swimming compared with the No CMS-Veh (immobility: $p<0.01$; swimming: $p=0.05$ ) and CMS-WIN (immobility and swimming: $p<0.05)$ groups. Also, the No CMS-Veh group demonstrated more climbing compared with the CMS-Veh and CMS-WIN groups $(p<0.05)$. Hence, CMS caused an increase in passive stress coping and a decrease in active stress coping, and intra-BLA WIN55,212-2 prevented some of these effects.

When coping behavior was tested on day 28, one-way ANOVA did not reveal a significant difference between the groups in immobility, climbing, or swimming $\left(\mathrm{F}_{(2,27}\right)<1$, NS) (Figure $4 \mathrm{~d}$ ). This suggests a significant recovery of coping behavior in the CMS group 1 week after the stress ended.

Other studies have shown that enhancing cannabinoid signaling had an antidepressant-like effect in the FST, when the drugs were injected between test sessions (Bambico et al, 2007; Gobbi et al, 2005; Hill and Gorzalka, 2005). Hence, we added an experiment in which we injected WIN55,212-2 IP immediately after the pre-test (with no previous CMS exposure) and tested the rats the day after (Figure 4e). ANOVA on stress-coping strategy revealed significant differences between the groups in immobility $\left(\mathrm{F}_{(1,17)}=4.386, \quad p=0.05\right)$ and climbing $\left(\mathrm{F}_{(1,17)}=4.605\right.$, $p<0.05)$. Hence, WIN55,212-2 reduced passive stress coping and increased active stress coping when administered systemically after the pre-test. Taken together, the results show that WIN55,212-2 administered during the last 3 days of CMS did not prevent the CMS-induced alterations in coping behavior. However, when administered systemically or locally into the BLA after the pre-test, WIN showed an antidepressant-like effect.

\section{The Effects of CMS and WIN55,212-2 on Sucrose Consumption and Weight Gain}

We have recently found that chronic exposure to restraint had no effect on despair-like behavior as measured in the FST and the sucrose consumption test $24 \mathrm{~h}, 10 \mathrm{~d}$, or $30 \mathrm{~d}$ after stress ended (Abush and Akirav, 2013). However, studies demonstrated that animals subjected to CMS show impairments in a variety of tests of rewarded behavior, including decreased intake and preference for sweet fluids (Grønli et al, 2004). It has been suggested that changes in sucrose intake may be artifacts related to loss of body weight (Matthews et al, 1995). To avoid this problem, we did a correction for body weight and measured sucrose intake/g of body weight. We also measured total fluid intake and found no differences between CMS and control rats in their water consumption throughout the experiment (averaged water consumption $\mathrm{ml} / \mathrm{kg}$ per day from day 0 to day 28: No CMS group: $78 \pm 4$; CMS group $=74.1 \pm 3.9$ ).

Mixed-design ANOVA (group $\times$ days $(3 \times 5)$ ) on sucrose intake revealed a significant difference between the groups $\left(\mathrm{F}_{(2,42)}=5.17, p=0.01\right)$ and a significant difference across the days $\left(\mathrm{F}_{(1,42)}=6.14, p=0.017\right)$, with no significant interaction effect $\left(\mathrm{F}_{(2,42)}=2.41\right.$, NS) (Figure 5a). Post hoc comparison indicated that the No CMS-Veh group consumed more sucrose compared with the CMS-Veh and CMS-WIN groups on days 7, $14(p<0.01)$, and $28(p<0.05)$.
Hence, WIN55,212-2 did not revert the CMS-induced effects on sucrose intake.

When testing the effects on body weight gain, mixeddesign ANOVA (group $\times$ days $(3 \times 5))$ revealed a significant difference between the groups $\left(\mathrm{F}_{(2,42)}=41.57, p<0.001\right)$, a significant within-subject effect for days $\left(\mathrm{F}_{(1,42)}=\right.$, $p<0.001)$, and a significant interaction $\left(\mathrm{F}_{(2,42)}=, p<.01\right)$ (Figure 5b). Post hoc comparison indicated that the No CMS-Veh group gained more weight compared with the CMS-Veh and CMS-WIN groups on days 7, 14, 21, and 28 $(p<0.05)$. Hence, WIN55,212-2 did not prevent the CMS-induced effects on weight gain.

\section{DISCUSSION}

CMS significantly modified physiological and behavioral reactions, as observed by the impairment in avoidance extinction and LTP in the hippocampal-accumbens pathway, and the alterations in depression-like symptoms, such as coping with stress behavior, weight gain, and sucrose consumption. The most significant effect observed in this study was that 3 days administration of the CB1/2 receptor agonist WIN55,212-2 or the GR antagonist RU-38486 prevented the CMS-induced alterations in emotional memory (ie, extinction) and plasticity. The preventive effect of WIN55,212-2 after CMS was found to be CB1 but not GR dependent.

\section{CMS and WIN55,212-2 Effects on Emotional Memory}

Exposure to CMS impaired extinction when tested 2 and 7 days after the stress ended. Delay in the extinction of fear memories has also been seen in patients with depressive syndrome and in rodents at high risk of signs of depression (Marsicano et al, 2002; Milad et al, 2006; Shumake et al, 2005). Mice with defects in cannabinoid receptors are characterized by high sensitivity to depressive-like responses in stress, and rats with innate learned helplessness are characterized by impaired extinction of conditioned fear reactions (Marsicano et al, 2002; Shumake et al, 2005). It has been suggested that 'depressed' rats may show impaired extinction as a result of negative evaluations of the environment and the development of the anhedonia typical of the depressive state (Anisman and Matheson, 2005).

Importantly, 3 days administration of WIN55,212-2 prevented the CMS-induced impairment of extinction tested 2 and 7 days after the last injection. This may have potential implications to developing pharmacological approaches to correct the prolonged retention of memories of negative events in depressive states.

WIN55,212-2 or AM251 administered for 3 days, with no stress exposure, had no effect on conditioning and extinction tested 7 days after injection but impaired fear retrieval when testing was performed 2 days after the last drug injection. Hence, it seems that cannabinoids have a different effect on behavior with or without stress exposure. This corroborates with our previous findings suggesting that the effects of WIN55,212-2 on memory and plasticity are quiet different when administered in proximity to stress exposure or without stress exposure (Abush and Akirav, 2013). We recently found that chronic WIN55,212-2 
administration (ie, 2 weeks) can impair object location short-term memory even 75 days after the last injection. However, when administered in proximity to chronic stress exposure, WIN55,212-2 can prevent the effects of stress on performance in this task (Abush and Akirav, 2013). Furthermore, acute intra-BLA WIN55,212-2 can prevent the effects of acute elevated platform stress on performance in an aversive learning task (Ganon-Elazar and Akirav, 2009), but acute intra-BLA WIN55,212-2 could not prevent the effects of the same stressor on the performance in a non-aversive task (Segev et al, 2012). In general, the cannabinoid system and the stress system are highly interconnected (Gorzalka et al, 2008; Hill and McEwen, 2010; Hill et al, 2010; Patel et al, 2004; Patel and Hillard, 2008), and it has been suggested that the eCB system might become activated specifically in highly aversive situations but not in non-aversive situations (Harloe et al, 2008; Holter et al, 2005).

\section{CMS and WIN55,212-2 Effects on Plasticity}

Exposure to CMS impaired LTP when tested 2 days, but not when tested 7 days, after the stress ended. This suggests a recovery of LTP one week after CMS ended. Many chronic stress paradigms produce changes that are dynamic and reversible (Conrad et al, 1999), suggesting that behavioral recovery is possible. Nevertheless, the exposure to CMS had significant effects on emotional learning and depression-like symptoms that suggest that some of the effects do not go through a habituation process and probably do not recover.

A similar result was found in CA1 slices; Holderbach et al (2007) found no effect on LTP tested within 8 days after the end of the CMS protocol. However, they found that CMS exposure facilitated CA1 LTD (Holderbach et al, 2007). On the other hand, Li et al (2012) exposed rats to 4 weeks of chronic unpredictable stress (CUMS) and 1 week later found impaired LTP in the CA1. The difference between the findings could result from the fact that we measured LTP in the NAc or because the CUMS involves the use of various physical and psychological stressors in a predetermined manner so that the animal is not able to adapt to the stressor. In the CMS model, the animal may develop some adaptation of the HPA axis as the same schedule is repeated for 3 weeks. Hence, some of the effects of CMS exposure may be short-lived.

It has been proposed that long-term synaptic plasticity or its modulation might be disturbed in depressed patients (Garcia, 2002; Stewart and Reid, 2002). Different antidepressants and electroconvulsive therapy have been shown to effectively modulate synaptic plasticity in the dentate gyrus and the CA1 and in the neostriatum (De Murtas et al, 2004; Stewart and Reid, 2000). Here we found an impaired ability to induce LTP in a brain circuit that may be crucially involved in the pathophysiology of major depression (Nestler and Carlezon, 2006).

WIN55,212-2 administered for 3 days, with no stress exposure, had no effect on LTP levels tested 2 days after the last injection. Previous studies have shown that WIN55,2122 administered acutely or chronically before HFS impair LTP in the hippocampus and NAc (Abush and Akirav, 2010, 2013; Terranova et al, 1995). When comparing our previous results (Abush and Akirav, 2013) with the results obtained here, different drug administration protocols (3 days vs 2 weeks), different testing times ( 2 days after the last injection $v s 24 \mathrm{~h}$ after the last injection) and different doses $(0.5 \mathrm{mg} /$ $\mathrm{kg}$ vs $1.2 \mathrm{mg} / \mathrm{kg}$ ) may explain the different effects of WIN55,212-2 on plasticity.

The prefrontal cortex (PFC), hippocampus, and amygdala, which densely innervate the NAc, show moderate-to-very high CB1 receptor levels, whereas in the NAc low levels of CB1 receptors were reported (Egertová and Elphick, 2000; Mailleux and Vanderhaeghen, 1992; Matsuda et al, 1993; Tsou et al, 1997). GRs, on the other hand, are abundant in the amygdala, hippocampus, NAc, and cerebral cortex (Ahima and Harlan, 1990). A previous study that specifically assessed the effects of stress on plasticity in the vSubNAc pathway (Dong et al, 2007) has shown that exposure to behavioral stress enabled low-frequency stimulation to induce long-term depression (LTD), and this stress-induced LTD was dependent on GRs.

NAc neuronal activation is subject to the competing drive of converging inputs from the PFC, vSub, and BLA (Belujon and Grace, 2008; Goto and Grace, 2005; Mulder et al, 1998; O’Donnell and Grace, 1994; O’Donnell and Grace, 1995). NAc lesions have been shown to block the acute memoryenhancing properties of glucocorticoids in the BLA, demonstrating a functional BLA-NAc interaction affecting memory formation (Roozendaal et al, 2001). Those properties might be dependent on the rapid non-genomic effects of glucocorticoids in the BLA that have been shown to be CB1 dependent (Campolongo et al, 2009). In the case of repeated stress such as CMS exposure, the effects on vSub-NAc plasticity may result from long-term changes in BLA GR and $\mathrm{CB} 1$ activity. In support of this, previous studies found that animals exposed to CMS show alterations in the expression of GRs and $\mathrm{CB} 1$ receptors in the hippocampus, NAc, and PFC (Bortolato et al, 2007; Guidotti et al, 2013; Hill et al, 2005; Hill et al, 2008).

Altered BLA function following exposure to repeated stress may mediate the effects of stress on vSub-NAc plasticity (Gill and Grace, 2011). Activating the amygdala (using HFS) can suppress vSub-evoked responses in the NAc (Gill and Grace, 2011) and repeated but not acute exposure to stress prevented potentiating the vSub-NAc pathway by HFS while causing a depression in the nontetanized BLA-NAc pathway (Gill and Grace, 2013). Cannabinoid agonists were found to presynaptically modulate GABAergic synaptic transmission in the amygdala and hippocampus and other brain areas (Chan et al, 1998; Hoffman and Lupica, 2001; Szabó et al, 1998; Takahashi and Linden, 2000; Vaughan et al, 1999, 2000). Katona et al (2001) found that WIN 55,212-2 significantly reduced the amplitude of $\mathrm{GABA}_{\mathrm{A}}$ receptor-mediated evoked IPSCs in the amygdala, which is in agreement with previous findings obtained in the hippocampus, which show presynaptic CB1 receptor localization on GABAergic axon terminals along with the inhibition of GABA release (Hájos et al, 2000; Hoffman and Lupica, 2000; Irving et al, 2000; Katona et al, 1999, 2000). Reich et al (2013) have recently shown that WIN 55,212-5 $(1 \mu \mathrm{M})$ after CMS exposure resulted in a significant increase in excitatory neurotransmission in the hippocampus; however, WIN 55,212-5 significantly decreased excitatory neurotransmission in CMS animals when $\mathrm{GABA}_{\mathrm{A}}$ neurotransmission in the hippocampus was 
blocked. Taken together, the data suggest that the preventing effects of WIN 55,212-5 on hippocampal-accumbens plasticity after stress may be mediated by its effect on GABAergic terminals in the BLA and hippocampus.

Nevertheless, several studies suggested that CB1-expressing neurons in the NAc, although sparse, are critical for cellular and behavioral alterations induced by cocaine and other drugs of abuse (Morra et al, 2010; Ramiro-Fuentes et al, 2010). Hence, the role of NAc-CB1 receptors in the preventing effects of WIN 55,212-5 on hippocampalaccumbens plasticity after stress cannot be excluded.

\section{Cannabinoids and Glucocorticoids}

The GR antagonist RU-38486 also prevented the CMSinduced alterations in emotional learning and plasticity. This corroborates with other studies showing that RU-38486 prevented stress-induced decreases in neuroplasticity as well as stress-induced increases in depression-like behaviors (de Kloet et al, 1988; Oomen et al, 2007; Wulsin et al, 2010). Taken together, our results suggest that both cannabinoids and GR blockers can be considered as therapeutic candidates for stress-induced conditions.

When RU-38486 was co-administered with WIN55,212-2 during the last 3 days of CMS, the beneficial effects on emotional learning and plasticity were maintained. This corroborates with a previous study in which chronic restraint stress reduced expression levels of GRs in the NAc, BLA, PFC, and hippocampus, and chronic administration of WIN55,212-2 (2 weeks) together with stress exposure did not affect this stress-induced decline in GRs in all the brain areas examined (Abush and Akirav, 2013). This suggests that the beneficial effects of WIN55,212-2 on memory and plasticity after chronic stress were not mediated by alterations in GR levels in the brain areas tested. Hence, the mechanism through which WIN55,212-2 prevents the CMS-induced memory and plasticity impairments is yet to be determined. One possible explanation could be that WIN55,212-2 affects systems that are activated by stress stimulation before the activation of the HPA axis, such as CRH or norepinephrine.

It has been hypothesized that the anxiolytic effects of cannabinoids are mediated via CB1 activation of GABAergic (Katona et al, 2001) or glucocorticoid (Rodriguez de Fonseca et al, 1996) mechanisms within the amygdala. WIN55,212-2 administered during stress exposure may reduce GABA release in BLA interneurons, thereby reducing their inhibition of the GABAergic neurons of the intercalated nuclei, which, in turn, increases their inhibition of the pyramidal neurons of the central amygdala (Katona et al, 2001). The end result may be reduced HPA axis activity and a reduction in the stress-induced increase in glucocorticoid levels. Glucocorticoids easily re-enter the brain to affect GRs in brain areas that are highly involved in memory processes (eg, the hippocampus and NAc). Hence, the reduction in HPA axis activity by cannabinoids or by GRs may prevent the effects of stress on memory and plasticity. In support of this, it has been shown that CB1 agonists decrease the excitability of projection neurons in the rat BLA (Pistis et al, 2004).

Several studies have shown that activating CB1 receptors or increasing $\mathrm{eCB}$ signaling prevents some of the effects of stress in the amygdala and hippocampus and can reduce stress-induced HPA axis activation (Ganon-Elazar and Akirav, 2009, 2012, 2013; Gorzalka et al, 2008; Patel et al, 2004). Nevertheless, other possible mechanisms could not be excluded; eg, RU-38486 can affect extinction and plasticity by regulating hippocampal neurogenesis. In support, it has been shown that RU-38486 rapidly reversed a chronic corticosterone-induced reduction of adult neurogenesis in rats (Mayer et al, 2006). Another possible explanation is that WIN55,212-2 administration induced long-term changes in endogenous cannabinoid signaling, ie, altering the expression of $\mathrm{CB} 1$ receptors in the relevant brain regions, that could have affected directly emotional memory and plasticity. In support of this, it has been demonstrated that CB1 receptors expression is altered in the amygdala and the hippocampus following stress (Hill et al, 2005; Zoppi et al, 2011). Specifically, exposure to CMS resulted in reduced $\mathrm{CB} 1$ receptor binding and protein expression in the hippocampus (Hill et al, 2005; Hill et al, 2008). CMS was also shown to produce an increase in CB1 receptor mRNA and $\mathrm{CB} 1$ receptor binding in the $\mathrm{PFC}$, whereas in NAc, CMS reduced $\mathrm{CB} 1$ receptor binding (Bortolato et al, 2007; Hill et al, 2008).

\section{CMS and WIN55,212-2 Effects on Depression-Like Symptoms}

Exposure to CMS impaired coping strategies examined 2 days, but not 7 days, after CMS. The effects of CMS on sucrose consumption and weight gain lasted at least 1 week after the stress ended.

Several studies found alterations in sucrose intake and body weight (reviewed by Willner, 2005), and Willner et al (1996) summarized data from different laboratories using the CMS procedure and concluded that decreased hedonic sensitivity following CMS cannot be attributed to loss of body weight. In addition to measurement of responsiveness to rewards using the sucrose test, the FST measures despair and coping in an aversive situation. Several studies found increased immobility in the FST following CMS; however, most studies measured FST $24 \mathrm{~h}$ after the last stressor (Molina et al, 1994) or CMS exposure duration was significantly longer than in our study (7 weeks; Griebel et al, 2005).

The 3 days administration of WIN55,212-2 did not prevent the CMS-induced alterations in depression-like symptoms. Bortolato et al (2007) showed that daily administration of URB597 for 5 weeks corrected the reduction in body weight gain and sucrose intake induced by CMS. The difference between the studies could be due to the different drugs used. URB597 is a selective inhibitor of the enzyme fatty-acid amide hydrolase, which catalyzes the intracellular hydrolysis of the eCB anandamide. Another explanation could be the differences in injection protocols ( 5 weeks for URB597 vs 3 days for WIN55,212-2). Nevertheless, we observed an antidepressant like effect when WIN55,212-2 was injected between test sessions, corroborating with previous studies (Bambico et al, 2007; Gobbi et al, 2005; Hill and Gorzalka, 2005).

There is substantial evidence supporting the involvement of the eCB system in both motivation to feed (hedonic properties) and energy metabolism, and one of the effects of 
chronic treatment with WIN 55,212-2 is increased appetite and food consumption (Di Marzo and Matias, 2005). Hence, chronic administration of WIN55,212-2 would probably overcome the CMS-induced decrease in weight gain.

It should be noted that responding to natural and artificial rewards, including sucrose intake, is mediated by the NAc and its dopaminergic inputs (Nestler et al, 2002), which is probably different from the neural substrate that mediates hippocampal-accumbens LTP, which is NMDA dependent (Dong et al, 2007).

\section{Summary}

WIN 55,212-2 can prevent the effects of different stressors on physiology and behavior (Abush and Akirav, 2013; Ganon-Elazar and Akirav, 2009, 2012, 2013; Ramot and Akirav, 2012). The preventing effects of WIN 55,212-2 are mediated by $\mathrm{CB} 1$ receptors, and in some of the stress paradigms (see Ganon-Elazar and Akirav, 2013) this effect is mediated by GRs in the amygdala and hippocampus. Here, cannabinoid receptor activation prevented the effects of CMS exposure on emotional learning and LTP in a brain circuit relevant to motivation and emotions. This suggests that cannabinoids could represent a novel approach to the treatment of cognitive deficits that accompany stressrelated depression.

\section{FUNDING AND DISCLOSURE}

The authors declare no conflict of interest.

\section{ACKNOWLEDGEMENTS}

This research was supported by THE ISRAEL SCIENCE FOUNDATION grant No. 222/08 to IA and by a grant from the Hope for Depression Research Foundation to GR-L.

\section{REFERENCES}

Abush H, Akirav I (2010). Cannabinoids modulate hippocampal memory and plasticity. Hippocampus 20: 1126-1138.

Abush H, Akirav I (2012). Short- and long-term cognitive effects of chronic cannabinoids administration in late-adolescence rats. PLoS One 7: e31731.

Abush H, Akirav I (2013). Cannabinoids ameliorate impairments induced by chronic stress to synaptic plasticity and short-term memory. Neuropsychopharmacology 38: 1521-1534.

Ahima R, Harlan R (1990). Charting of type II glucocorticoid receptor-like immunoreactivity in the rat central nervous system. Neuroscience 39: 579-604.

Akirav I (2013). Cannabinoids and glucocorticoids modulate emotional memory after stress. Neurosci Biobehav Rev (e-pub ahead of print).

Anisman H, Matheson K (2005). Stress, depression, and anhedonia: caveats concerning animal models. Neurosci Biobehav Res 29: 525-546.

Atsak P, Roozendaal B, Campolongo P (2012). Role of the endocannabinoid system in regulating glucocorticoid effects on memory for emotional experiences. J Neurosci 1: 104-116.

Bambico FR, Katz N, Debonnel G, Gobbi G (2007). Cannabinoids elicit antidepressant-like behavior and activate serotonergic neurons through the medial prefrontal cortex. J Neurosci 27: $11700-11711$.
Belujon P, Grace AA (2008). Critical role of the prefrontal cortex in the regulation of hippocampus-accumbens information flow. J Neurosci 28: 9797-9805.

Bortolato M, Mangieri RA, Fu J, Kim JH, Arguello O, Duranti A et al (2007). Antidepressant-like activity of the fatty acid amide hydrolase inhibitor URB597 in a rat model of chronic mild stress. Biol Psychiatry 62: 1103-1110.

Campolongo P, Roozendaal B, Trezza V, Hauer D, Schelling G, McGaugh JL et al (2009). Endocannabinoids in the rat basolateral amygdala enhance memory consolidation and enable glucocorticoid modulation of memory. Proc Natl Acad Sci USA 106: $4888-4893$.

Chan PK, Chan SC, Yung WH (1998). Presynaptic inhibition of GABAergic inputs to rat substantia nigra pars reticulata neurones by a cannabinoid agonist. Neuroreport 9: 671-675.

Conrad CD, LeDoux JE, Magariños AM, McEwen BS (1999). Repeated restraint stress facilitates fear conditioning independently of causing hippocampal CA3 dendritic atrophy. Behav Neurosci 113: 902-913.

de Bitencourt R, Pamplona FA, Takahashi RN (2013). A current overview of cannabinoids and glucocorticoids in facilitating extinction of aversive memories: potential extinction enhancers. Neuropharmacology 64: 389-395.

de Kloet ER, de Kock S, Schild V, Veldhuis HD (1988). Antiglucocorticoid RU 38486 attenuates retention of a behaviour and disinhibits the hypothalamic-pituitary-adrenal axis at different brain sites. Neuroendocrinology 47: 109-115.

De Murtas M, Tatarelli R, Girardi P, Vicini S (2004). Repeated electroconvulsive stimulation impairs long-term depression in the neostriatum. Biol Psychiatry 55: 472-476.

Diamond DM, Campbell AM, Park CR, Halonen J, Zoladz PR (2007). The temporal dynamics model of emotional memory processing: a synthesis on the neurobiological basis of stressinduced amnesia, flashbulb and traumatic memories, and the Yerkes-Dodson law. Neural Plast 2007: 60803.

Di Marzo V, Matias I (2005). Endocannabinoid control of food intake and energy balance. Nat Neurosci 8: 585-589.

Dong Z, Cao J, Xu L (2007). Opiate withdrawal modifies synaptic plasticity in subicular-nucleus accumbens pathway in vivo. Neuroscience 144: 845-854.

Egertová M, Elphick MR (2000). Localisation of cannabinoid receptors in the rat brain using antibodies to the intracellular C-terminal tail of CB1. J Comp Neurol 422: 159-171.

Ganon-Elazar E, Akirav I (2009). Cannabinoid receptor activation in the basolateral amygdala blocks the effects of stress on the conditioning and extinction of inhibitory avoidance. J Neurosci 29: 11078-11088.

Ganon-Elazar E, Akirav I (2012). Cannabinoids prevent the development of behavioral and endocrine alterations in a rat model of intense stress. Neuropsychopharmacology 37: 456-466.

Ganon-Elazar E, Akirav I (2013). Cannabinoids and traumatic stress modulation of contextual fear extinction and GR expression in the amygdala-hippocampal-prefrontal circuit. Psychoneuroendocrinology 38: 1675-1687.

Garcia R (2002). Stress, synaptic plasticity, and psychopathology. Rev Neurosci 13: 195-208.

Gill KM, Grace AA (2011). Heterogeneous processing of amygdala and hippocampal inputs in the rostral and caudal subregions of the nucleus accumbens. Int J Neuropsychopharmacol 14: 1301-1314.

Gill KM, Grace AA (2013). Differential effects of acute and repeated stress on hippocampus and amygdala inputs to the nucleus accumbens shell. Int J Neuropsychopharmacol 16: 2013-2025.

Gobbi G, Bambico FR, Mangieri R, Bortolato M, Campolongo P, Solinas $M$ et al (2005). Antidepressant-like activity and modulation of brain monoaminergic transmission by blockade of anandamide hydrolysis. PNAS 102: 18620-18625. 
Gorzalka BB, Hill MN, Hillard CJ (2008). Regulation of endocannabinoid signaling by stress: implications for stress-related affective disorders. Neurosci Biobehav Rev 32: 1152-1160.

Goto Y, Grace AA (2005). Dopamine-dependent interactions between limbic and prefrontal cortical plasticity in the nucleus accumbens: disruption by cocaine sensitization. Neuron 47: 255-266.

Griebel G, Stemmelin J, Scatton B (2005). Effects of the cannabinoid $\mathrm{CB} 1$ receptor antagonist rimonabant in models of emotional reactivity in rodents. Biol Psychiatry 3: 261-267.

Grønli J, Murison R, Bjorvatn B, Sørensen E, Portas CM, Ursin R. (2004). Chronic mild stress affects sucrose intake and sleep in rats. Behav Brain Research 150: 139-147.

Guidotti G, Calabrese F, Anacker C, Racagni G, Pariante CM, Riva MA (2013). Glucocorticoid receptor and FKBP5 expression is altered following exposure to chronic stress: modulation by antidepressant treatment. Neuropsychopharmacology 38: 616-627.

Hájos N, Katona I, Naiem SS, Mackie K, Ledent C, Mody I et al (2000). Cannabinoids inhibit hippocampal GABAergic transmission and network oscillations. Eur J Neurosci 12: 3239-3249.

Haller J, Bakos N, Szirmay M, Ledent C, Freund TF (2002). The effects of genetic and pharmacological blockade of the $\mathrm{CB}_{1}$ cannabinoid receptor on anxiety. Euro J Neurosci 16: 1395-1398.

Harloe JP, Thorpe AJ, Lichtman AH (2008). Differential endocannabinoid regulation of extinction in appetitive and aversive Barnes maze tasks. Learn Mem 15: 806-809.

Hill MN, Carrier EJ, Ho WS, Shi L, Patel S, Gorzalka BB et al (2008). Prolonged glucocorticoid treatment decreases cannabinoid CB1 receptor density in the hippocampus. Hippocampus 18: 221-226.

Hill MN, Gorzalka BB (2005). Is there a role for the endocannabinoid system in the etiology and treatment of melancholic depression? Behav Pharmacol 16: 333-352.

Hill MN, Ho WS, Meier SE, Gorzalka BB, Hillard CJ (2005). Chronic corticosterone treatment increases the endocannabinoid 2-arachidonylglycerol in the rat amygdala. Eur J Pharmacol 528: 99-102.

Hill MN, McEwen BS (2010). Involvement of the endocannabinoid system in the neurobehavioural effects of stress and glucocorticoids. Prog Neuropsychopharmacol Biol Psychiatry 34: 791-797.

Hill MN, McLaughlin RJ, Bingham B, Shrestha L, Lee TT, Gray JM et al (2010). Endogenous cannabinoid signaling is essential for stress adaptation. PNAS 107: 9406-9411.

Hill MN, McLaughlin RJ, Morrish AC, Viau V, Floresco SB, Hillard CJ et al (2009). Suppression of amygdalar endocannabinoid signaling by stress contributes to activation of the hypothalamic-pituitary-adrenal axis. Neuropsychopharmacology 34: 2733-2745.

Hill MN, McLaughlin RJ, Pan B, Fitzgerald ML, Roberts CJ, Lee TT et al (2011). Recruitment of prefrontal cortical endocannabinoid signaling by glucocorticoids contributes to termination of the stress response. J Neurosci 31: 10506-10515.

Hoffman AF, Lupica CR (2000). Mechanisms of cannabinoid inhibition of GABA(A) synaptic transmission in the hippocampus. J Neurosci 20: 2470-2479.

Hoffman AF, Lupica CR (2001). Direct actions of cannabinoids on synaptic transmission in the nucleus accumbens: a comparison with opioids. J Neurophysiol 85: 72-83.

Holderbach R, Clark K, Moreau JL, Bischofberger J, Normann C (2007). Enhanced long-term synaptic depression in an animal model of depression. Biol Psychiatry 62: 92-100.

Holter SM, Kallnik M, Wurst W, Marsicano G, Lutz B, Wotjak CT (2005). Cannabinoid CB1 receptor is dispensable for memory extinction in an appetitively-motivated learning task. Eur $J$ Pharmacol 510: 69-74.

Irving AJ, Coutts AA, Harvey J, Rae MG, Mackie K, Bewick GS et al (2000). Functional expression of cell surface cannabinoid CB(1) receptors on presynaptic inhibitory terminals in cultured rat hippocampal neurons. Neuroscience 98: 253-262.
Katona I, Rancz EA, Acsady L, Ledent C, Mackie K, Hajos N et al (2001). Distribution of CB1 cannabinoid receptors in the amygdala and their role in the control of GABAergic transmission. J Neurosci 21: 9506-9518.

Katona I, Sperlágh B, Sik A, Köfalvi A, Vizi ES, Mackie K et al (1999). Presynaptically located CB1 cannabinoid receptors regulate GABA release from axon terminals of specific hippocampal interneurons. J Neurosci 19: 4544-4558.

Katona I, Sperlágh B, Maglóczky Z, Sántha E, Köfalvi A, Czirják S et al (2000). GABAergic interneurons are the targets of cannabinoid actions in the human hippocampus. Neuroscience 100: 797-804.

Li W, Liu L, Liu YY, Luo J, Lin JY, Li X et al (2012). Effects of electroconvulsive stimulation on long-term potentiation and synaptophysin in the hippocampus of rats with depressive behavior. J ECT 28: 111-117.

Lutz B (2009). Endocannabinoid signals in the control of emotion. Curr Opin Pharmacol 9: 46-52.

Macrì S, Laviola G (2004). Single episode of maternal deprivation and adult depressive profile in mice: interaction with cannabinoid exposure during adolescence. Behav Brain Res 154: 231-238.

Mailleux P, Vanderhaeghen JJ (1992). Distribution of neuronal cannabinoid receptor in the adult rat brain: a comparative receptor binding radioautography and in situ hybridization histochemistry. Neuroscience 48: 655-668.

Marsicano G, Wotjak CT, Azad SC, Bisogno T, Rammes G, Cascio MG et al (2002). The endogenous cannabinoid system controls extinction of aversive memories. Nature 418: 530-534.

Martin M, Ledent C, Parmentier M, Maldonado R, Valverde O (2002). Involvement of $\mathrm{CB}_{1}$ cannabinoid receptors in emotional behaviour. Psychopharmacology 159: 379-387.

Matsuda LA, Bonner TI, Lolait SJ (1993). Localization of cannabinoid receptor mRNA in rat brain. J Comp Neurol 327: $535-550$.

Matthews K, Forbes N, Reid IC (1995). Sucrose consumption as a hedonic measure following chronic unpredictable mild stress. Physiol Behav 57: 241-248.

Mayer JL, Klumpers L, Maslam S, de Kloet ER, Joëls M, Lucassen PJ (2006). Brief treatment with the glucocorticoid receptor antagonist mifepristone normalises the corticosterone-induced reduction of adult hippocampal neurogenesis. Neuroendocrinol 18: 629-631.

Milad MR, Rauch SL, Pitman RK, Quirk GJ (2006). Fear extinction in rats: implications for human brain imaging and anxiety disorders. Biol Psychology 73: 61-71.

Molina VA, Heyser CJ, Spear LP (1994). Chronic variable stress or chronic morphine facilitates immobility in a forced swim test: reversal by naloxone. Psychopharmacology 114: 433-440.

Morra JT, Glick SD, Cheer JF (2010). Neural encoding of psychomotor activation in the nucleus accumbens core, but not the shell, requires cannabinoid receptor signaling. J Neurosci 30: 5102-5107.

Mulder AB, Hodenpijl MG, Lopes da Silva FH (1998). Electrophysiology of the hippocampal and amygdaloid projections to the nucleus accumbens of the rat: convergence, segregation, and interaction of inputs. J Neurosci 18: 5095-5102.

Nestler EJ, Barrot M, DiLeone RJ, Eisch AJ, Gold SJ, Monteggia LM (2002). Neurobiology of depression. Neuron 34: 13-25.

Nestler EJ, Carlezon WA Jr (2006). The mesolimbic dopamine reward circuit in depression. Biol Psychiatry 59: 1151-1159.

O’Donnell P, Grace AA (1994). Tonic D2-mediated attenuation of cortical excitation in nucleus accumbens neurons recorded in vitro. Brain Res 634: 105-112.

O’Donnell P, Grace AA (1995). Synaptic interactions among excitatory afferents to nucleus accumbens neurons: hippocampal gating of prefrontal cortical input. J Neurosci 15: 3622-3639.

Oomen JL, Mayer ER, de Kloet CA, Joels PJ, Lucassen M (2007). Brief treatment with the glucocorticoid receptor antagonist 
mifepristone normalizes the reduction in neurogenesis after chronic stress. Eur J Neurosci 26: 3395-3401.

Patel S, Roelke CT, Rademacher DJ, Cullinan WE, Hillard CJ (2004). Endocannabinoid signaling negatively modulates stressinduced activation of the hypothalamic-pituitary-adrenal axis. Endocrinology 145: 5431-5438.

Patel S, Hillard CJ (2008). Adaptations in endocannabinoid signaling in response to repeated homotypic stress: a novel mechanism for stress habituation. Eur J Neurosci 27: 2821-2829.

Pistis M, Perra S, Pillolla G, Melis M, Gessa GL, Muntoni AL (2004). Cannabinoids modulate neuronal firing in the rat basolateral amygdala: evidence for CB1- and non-CB1-mediated actions. Neuropharmacology 46: 115-125.

Rademacher DJ, Meier SE, Shi L, Ho WS, Jarrahian A, Hillard CJ (2008). Effects of acute and repeated restraint stress on endocannabinoid content in the amygdala, ventral striatum, and medial prefrontal cortex in mice. Neuropharmacology 54: 108-116.

Ramiro-Fuentes S, Ortiz O, Moratalla R, Fernandez-Espejo E (2010). Intra-accumbens rimonabant is rewarding but induces aversion to cocaine in cocaine-treated rats, as does in vivo accumbal cannabinoid CB1 receptor silencing: critical role for glutamate receptors. Neuroscience 167: 205-215.

Ramot A, Akirav I (2012). Cannabinoid receptors activation and glucocorticoid receptors deactivation in the amygdala prevent the stress-induced enhancement of a negative learning experience. Neurobiol Learn Mem 97: 393-401.

Reich CG, Mihalik GR, Iskander AN, Seckler JC, Weiss MS (2013). Adolescent chronic mild stress alters hippocampal CB1 receptormediated excitatory neurotransmission and plasticity. Neuroscience 253C: 444-454.

Rodriguez de Fonseca F, Rubio P, Menzaghi F, Merlo-Pich E, Rivier J, Koob GF et al (1996). Corticotropin-releasing factor (CRF) antagonist [D-Phe12, Nle21, 38, C alpha MeLeu37] CRF attenuates the acute actions of the highly potent cannabinoid receptor agonist HU-210 on defensive-withdrawal behavior in rats. J Pharmacol Exp Ther 276: 56-64.

Roozendaal B, de Quervain DJ-F, Ferry B, Setlow B, McGaugh JL (2001). Basolateral amygdala-nucleus accumbens interactions in mediating glucocorticoid enhancement of memory consolidation. J Neurosci 21: 2518-2525.

Segev A, Ramot A, Akirav I (2012). Stress hormones receptors in the amygdala mediate the effects of stress on the consolidation, but not the retrieval, of a non aversive spatial task. PLoS One 7: e29988.

Shumake J, Barrett D, Gonzalez-Lima F (2005). Behavioral characteristics of rats predisposed to learned helplessness: reduced reward sensitivity, increased novelty seeking, and persistent fear memories. Behav Brain Res 164: 222-230.
Stewart CA, Reid IC (2000). Repeated ECS and fluoxetine administration have equivalent effects on hippocampal synaptic plasticity. Psychopharmacology 148: 217-223.

Stewart CA, Reid IC (2002). Antidepressant mechanisms: functional and molecular correlates of excitatory amino acid neurotransmission. Mol Psychiatry 7: 15-22.

Szabó B, Dorner L, Pfreundtner C, Norenberg W, Starke K (1998). Inhibition of GABAergic inhibitory postsynaptic currents by cannabinoids in rat corpus striatum. Neuroscience 85: 395-403.

Takahashi KA, Linden DJ (2000). Cannabinoid receptor modulation of synapses received by cerebellar Purkinje cells. J Neurophysiol 83: 1167-1180.

Terranova JP, Michaud JC, Le Fur G, Soubrie P (1995). Inhibition of long-term potentiation in rat hippocampal slices by anandamide and WIN55212-2: Reversal by SR141716 A, a selective antagonist of CB1 cannabinoid receptors. Naunyn Schmiedebergs Arch Pharmacol 352: 576-579.

Tsou K, Brown S, Saņudo-Peņa M, Mackie K, Walker J (1997). Immunohistochemical distribution of cannabinoid CB1 receptors in the rat central nervous system. Neuroscience 83: 393-411.

Vaughan CW, Connor M, Bagley EE, Christie MJ (2000). Actions of cannabinoids on membrane properties and synaptic transmission in rat periaqueductal gray neurons in vitro. Mol Pharmacol 57: 288-295.

Vaughan CW, McGregor IS, Christie MJ (1999). Cannabinoid receptor activation inhibits GABAergic neurotransmission in rostral ventromedial medulla neurons in vitro. $\mathrm{Br} J$ Pharmacol 127: 935-940.

Viveros MP, Marco EM, File SE (2005). Endocannabinoid system and stress and anxiety responses. Pharmacol Biochem Behav 81: 331-342.

Willner P (2005). Chronic mild stress (CMS) revisited: consistency and behavioural-neurobiological concordance in the effects of CMS. Neuropsychobiology 52: 90-110.

Willner P, Muscat R, Papp M (1992). Chronic mild stress-induced anhedonia: a realistic animal model of depression. Neurosci Biobehav Rev 16: 525-534.

Willner P, Moreau JL, Nielsen CK, Papp M, Sluzewska A (1996). Decreased hedonic responsiveness following chronic mild stress is not secondary to loss of body weight. Physiol Behav 60: 129-134.

Wulsin AC, Herman JP, Solomon MB (2010). Mifepristone decreases depression-like behavior and modulates neuroendocrine and central hypothalamic-pituitary-adrenocortical axis responsiveness to stress. Psychoneuroendocrinology 35: 1100-1112.

Zoppi S, Pérez Nievas BG, Madrigal JL, Manzanares J, Leza JC, García-Bueno B (2011). Regulatory role of cannabinoid receptor 1 in stress-induced excitotoxicity and neuroinflammation. Neuropsychopharmacology 36: 805-818. 